\title{
Small Molecule Inhibitors of Bacterial Quorum Sensing and Biofilm Formation
}

\author{
Grant D. Geske, Rachel J. Wezeman, Adam P. Siegel and Helen E. Blackwell* \\ Department of Chemistry, University of Wisconsin-Madison, \\ 1101 University Avenue, Madison, WI 53706-1322 \\ e-mail: blackwell@chem.wisc.edu
}

\section{Supporting Information.}

General experimental information

S-2

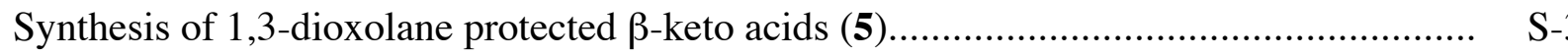

Synthesis of natural and unnatural AHLs $(\mathbf{7 a}-\mathbf{7 q}, \mathbf{8 a}-\mathbf{h})$....................................... S-5

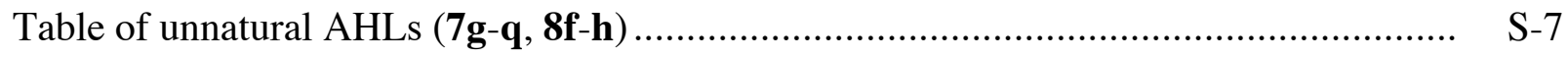

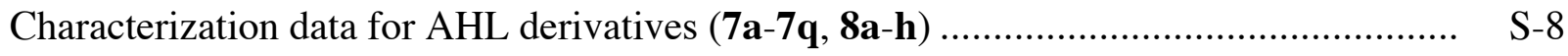

Biological screening protocols and supplementary assay data ................................ S-20

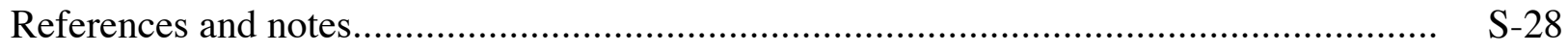

* To whom correspondence should be addressed. 


\section{General experimental information}

General. ${ }^{1} \mathrm{H}$ NMR and ${ }^{13} \mathrm{C}$ NMR spectra were recorded on a Bruker AC-300 spectrometer in deuterated solvents at $300 \mathrm{MHz}$ and $75 \mathrm{~Hz}$, respectively. Chemical shifts are reported in parts per million (ppm, $\delta)$ using tetramethyl silane (TMS) as an internal reference $(0.0 \mathrm{ppm})$. Couplings are reported in hertz. Electrospray ionization (ESI) MS were obtained using a Shimadzu LCMS2010 system (Columbia, MD) equipped with two pumps (LC-10ADvp), controller (SCL10Avp), autoinjector (SIL-10ADvp), UV diode array detector (SPD-M10Avp), and single quadrupole analyzer. FT-IR and attenuated total reflectance (ATR)-IR spectra were recorded with a Bruker Tensor 27 spectrometer, outfitted with a single reflection MIRacle Horizontal ATR unit from Pike Technologies. A ZnSe crystal with spectral range 20,000 to $650 \mathrm{~cm}^{-1}$ was used for ATR-IR measurements. UV spectra were recorded using an HP-8452 UV-Visible spectrometer running Chemstation software. GC-MS data were obtained using a Shimadzu GC17A system (Columbia, MD) equipped with a QP-5000 mass spectrometer. A Restek RTX-5 cross bond $95 \%$ polysiloxane GC column was used with following general GC gradient: injection temperature $300{ }^{\circ} \mathrm{C}$; initial oven temperature $100{ }^{\circ} \mathrm{C}$; hold $3 \mathrm{~min}$; ramp at $20{ }^{\circ} \mathrm{C} / \mathrm{min}$ to $300{ }^{\circ} \mathrm{C}$; hold 2-15 min for a total run time of 15-30 min. Optical rotations $\left([\alpha]_{24 \mathrm{D}}\right)$ were measured on a Perkin-Elmer 241 digital polarimeter at $25^{\circ} \mathrm{C}$.

All reagents were purchased from commercial sources (Alfa-Aesar, Aldrich, Acros, and Sigma) and used without further purification. Solvents were purchased from commercial sources (Aldrich and J.T. Baker) and used as is, with the exception of dichloromethane $\left(\mathrm{CH}_{2} \mathrm{Cl}_{2}\right)$, which was distilled over calcium hydride immediately prior to use. All solid-phase syntheses were performed using aminomethyl polystyrene resin (NovaBiochem, 100-200 mesh; loading 1.1-1.2 $\mathrm{mmol} / \mathrm{g})$.

Microwave instrumentation. Solid-phase reactions were carried out using either Milestone or CEM commercial microwave (MW) reactors (Figure S-1). The Milestone MicroSYNTH Labstation is a multimodal MW synthesis reactor equipped with a continuous power source (1000 W max). ${ }^{1}$ This instrument is interfaced with an Ethos MicroSYNTH Lab Terminal PC running EasyWave reaction monitoring software. Using this reactor system, MW irradiation can be applied to reactions using either wattage (power) control or temperature control. The MW reactor is equipped with a fiber-optic temperature sensor that allows direct monitoring of the internal temperature of reaction vessels, and an infrared sensor (installed in the side wall of the reactor cavity) that monitors the surface temperature of any reaction vessel inside the cavity. The system also has a rotating plate in the cavity and the capability for stirring (using magnetic stirbars) during reactions.

The CEM Discover is a monomodal MW synthesis reactor equipped with a $300 \mathrm{~W}$ (max) power source. ${ }^{2}$ The system has an attached Explorer automated synthesis workstation module, with four autosampler racks that each hold six samples. The instrument is interfaced with a Dell Inspiron PC running ChemDriver Discovery reaction monitoring software. Using this system, MW irradiation can be applied to reactions using wattage, pressure, or temperature control. The CEM MW reactor is equipped with an infrared temperature sensor positioned below the reaction vessel to control temperature. The system also has the capability for stirring (using magnetic stirbars) during reactions. 
All MW-assisted reactions reported in this study were performed using temperature control to monitor and control MW irradiation.
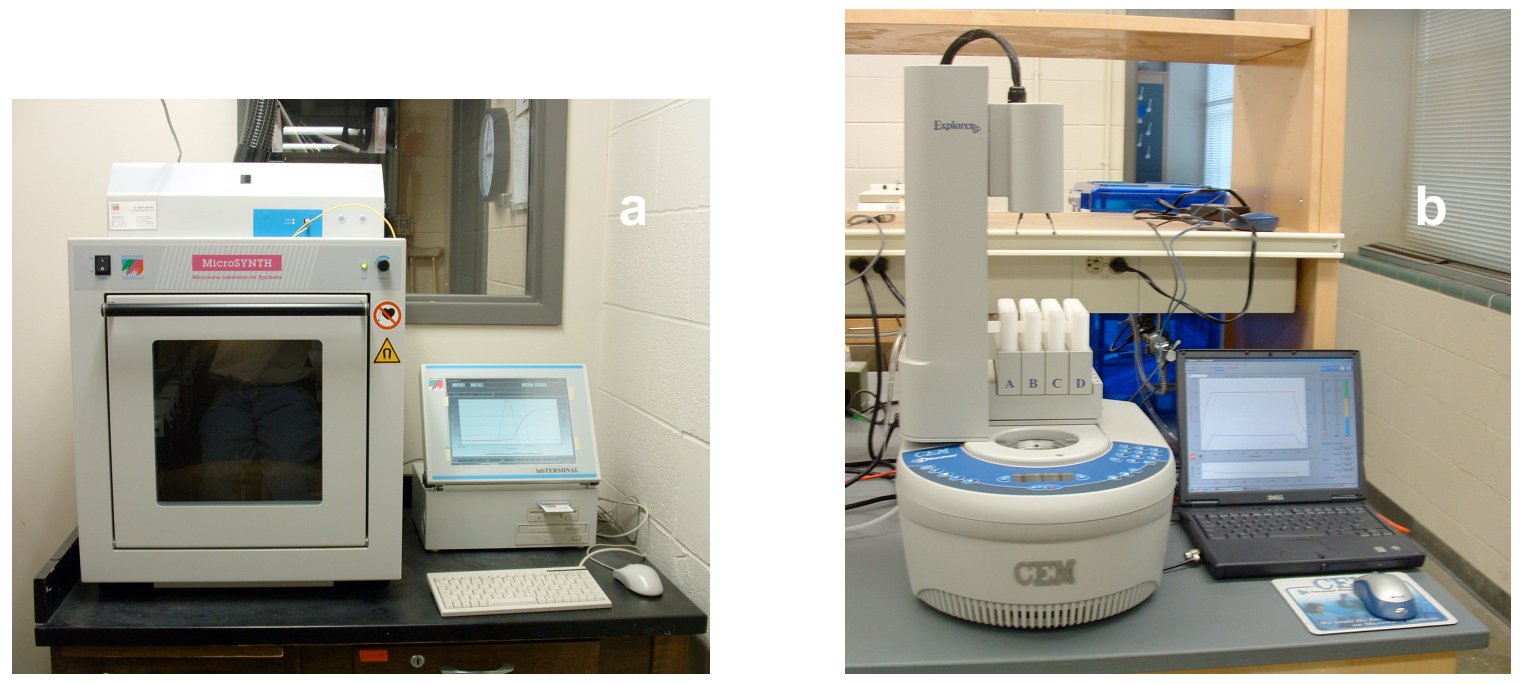

Figure S-1. Microwave instrumentation used in this study. a. Milestone Microsynth Labstation. b. CEM Discover with Explorer automated synthesis workstation.

Solid-phase library synthesis techniques. Solid-phase reactions were performed in either $100 \mathrm{~mL}$ round bottom flasks in the Milestone MW reactor or $10 \mathrm{~mL}$ glass CEM MW vessels (part \# 908035) in the CEM MW reactor. Between synthesis steps, the solid-phase resin was washed with solvents stored in standard polypropylene Nalgene squirt bottles on a Vac-Man vacuum manifold (Promega, part \#: A7231) using $8 \mathrm{~mL}$ polypropylene sample reservoirs (Alltech, part \#: 210208) equipped with $20 \mu \mathrm{m}$ frits (Alltech, part \#: 211408). Liquid reagents were dispensed during synthesis using Brinkman Eppendorf pipettmen (calibrated for variable solvent delivery) equipped with disposable polypropylene pipette tips.

\section{Synthesis of 1,3-dioxolane protected $\beta$-keto acids}

The 1,3-dioxolane protected $\beta$-keto acids building blocks (5) used in this study were prepared via a modified version of the methods reported by Barnick and Rathke. ${ }^{3}$ A representative synthesis is outlined below.

Synthesis of 3-oxooctanoic acid (10b). A stirred solution of bis-trimethylsilyl malonate $(21.6 \mathrm{~g}, 71.5 \mathrm{mmol})$ in $100 \mathrm{~mL}$ of anhydrous diethyl ether was cooled to $-78{ }^{\circ} \mathrm{C}$. To this solution, $n$-butyl lithium (1.6 $\mathrm{M}$ in ether, $44.7 \mathrm{~mL}, 71.5 \mathrm{mmol}$ ) was added slowly, keeping the temperature below $-60^{\circ} \mathrm{C}$. Upon completion of addition, the reaction was allowed to warm to $-10^{\circ} \mathrm{C}$, at which time hexanoyl chloride $(5 \mathrm{~mL}, 35.75 \mathrm{mmol})$ was added quickly and allowed to stir for $30 \mathrm{~min}$. Next, $150 \mathrm{~mL}$ of a cold, aq. $5 \%$ sodium bicarbonate solution was added, and the resulting solution was stirred vigorously for $30 \mathrm{~min}$. The aq. layer was separated out and acidified with cold $4 \mathrm{~N}$ sulfuric acid until $\mathrm{pH}=2$. The aq. layer was then extracted $2 \times 50 \mathrm{~mL}$ with diethyl ether, dried over $\mathrm{MgSO}_{4}$, and concentrated down in vacuo to afford a white solid. This solid could be further purified by recrystallization from hexane, if necessary. $4.9 \mathrm{~g}, 87 \%$ yield. 
${ }^{1} \mathrm{H}$ NMR $\left(300 \mathrm{MHz}, \mathrm{CDCl}_{3}\right) \delta=3.49\left(\mathrm{~s}, 2 \mathrm{H}, \mathrm{CH}_{2}\right), 2.59$ (t, 2H, J=7.3 Hz, $\left.\mathrm{CH}_{2}\right), 1.64$ (p, 2H, J=7.4 $\left.\mathrm{Hz}, \mathrm{CH}_{2}\right), 1.34\left(\mathrm{~m}, 4 \mathrm{H}, \mathrm{CH}_{2} \mathrm{CH}_{2}\right), 0.92\left(\mathrm{t}, 3 \mathrm{H}, \mathrm{J}=6.9 \mathrm{~Hz}, \mathrm{CH}_{3}\right) ;{ }^{13} \mathrm{C} \mathrm{NMR}\left(75 \mathrm{MHz}, \mathrm{CDCl}_{3}\right)$ $\delta=204.4,182.8,87.9,48.1,43.4,31.3,23.5,14.1 \mathrm{ppm}$.

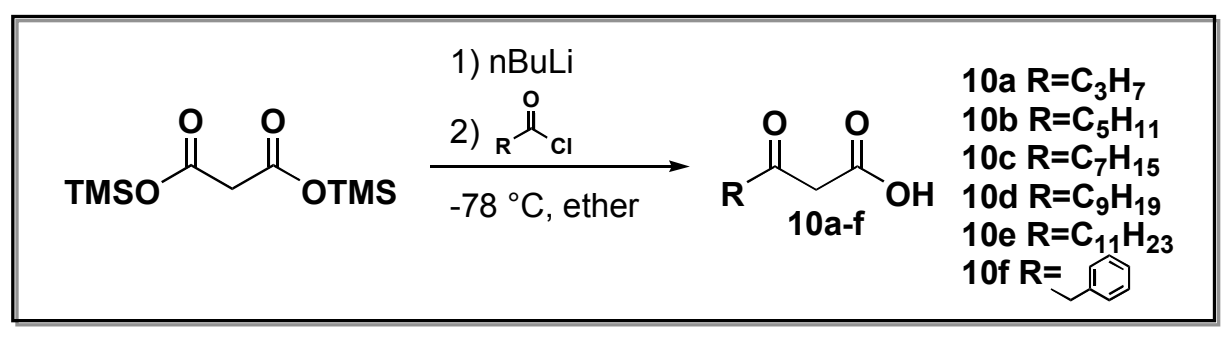

Synthesis of methyl-3-oxooctanoate (11b). To a stirred solution of $\mathbf{1 0 b}(5.5 \mathrm{~g}, 35 \mathrm{mmol})$ in $150 \mathrm{~mL}$ of a 4:1 mixture of benzene and methanol, $\mathrm{TMSCHN}_{2}$ in diethyl ether $(2 \mathrm{M}, 21 \mathrm{~mL}, 42$ mmol) was added over a period of $10 \mathrm{~min}$. The reaction was allowed to stir for $30 \mathrm{~min}$, after which the reaction mixture was concentrated in vacuo to afford $\mathbf{1 1 b}$ as a yellow oil. This material was used in the subsequent step with no further purification. $6.1 \mathrm{~g}, 95 \%$ yield. ${ }^{1} \mathrm{H}$ NMR (300 $\left.\mathrm{MHz}, \mathrm{CDCl}_{3}\right) \delta=3.73\left(\mathrm{~s}, 3 \mathrm{H}, \mathrm{CH}_{3}\right) 3.44\left(\mathrm{~s}, 2 \mathrm{H}, \mathrm{CH}_{2}\right), 2.55\left(\mathrm{t}, 2 \mathrm{H}, \mathrm{J}=7.3 \mathrm{~Hz}, \mathrm{CH}_{2}\right), 1.64(\mathrm{p}, 2 \mathrm{H}$, $\left.\mathrm{J}=7.4 \mathrm{~Hz}, \mathrm{CH}_{2}\right), 1.36\left(\mathrm{~m}, 4 \mathrm{H}, \mathrm{CH}_{2} \mathrm{CH}_{2}\right), 0.91\left(\mathrm{t}, 3 \mathrm{H}, \mathrm{J}=6.9 \mathrm{~Hz}, \mathrm{CH}_{3}\right) ;{ }^{13} \mathrm{C} \mathrm{NMR}\left(75 \mathrm{MHz}, \mathrm{CDCl}_{3}\right)$ $\delta=202.9,167.9,128.5,52.7,49.2,43.2,31.3,23.3,14.0$ ppm.

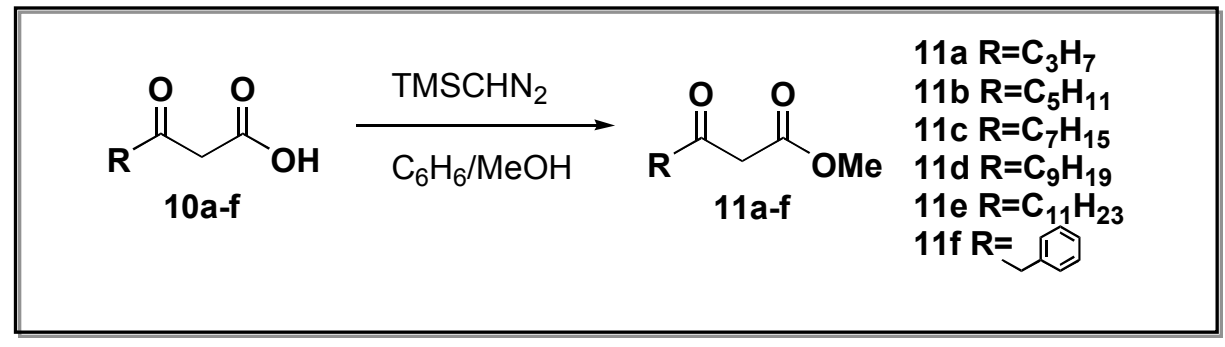

Synthesis of 3,3-ethylenedioxooctanoic acid (5b). To a stirred solution of methyl-3oxooctanoate (11b) $(5.6 \mathrm{~g}, 32.5 \mathrm{mmol})$ in $125 \mathrm{~mL}$ of benzene, ethylene glycol $(20.2 \mathrm{~g}, 325$ $\mathrm{mmol})$ and $p \mathrm{TsOH}(0.617 \mathrm{~g}, 3.25 \mathrm{mmol})$ was added. The flask was equipped with a condenser and Dean-Stark trap and heated to reflux for $24 \mathrm{~h}$. The reaction mixture was concentrated in vacuo and diluted in $100 \mathrm{~mL}$ of diethyl ether. The organic layer was washed with $2 \times 25 \mathrm{~mL}$ of $10 \%$ aq. $\mathrm{NaOH}$, then $2 \times 25 \mathrm{~mL}$ of saturated $\mathrm{NaCl}$ solution, dried over $\mathrm{MgSO}_{4}$, and concentrated in vacuo to afford a clear oil. This oil was subjected to saponification by treatment with $1 \mathrm{~N}$ $\mathrm{NaOH}(150 \mathrm{~mL})$ and $\mathrm{MeOH}(75 \mathrm{~mL})$ for $6 \mathrm{~h}$. The basic solution was concentrated in vacuo, chilled in an ice bath, and acidified with cold concentrated $\mathrm{HCl}$ to a $\mathrm{pH}=2$. The acidified solution was extracted with $2 \times 75 \mathrm{~mL}$ of diethyl ether, dried over $\mathrm{MgSO}_{4}$, and concentrated in vacuo to afford the title compound $\mathbf{5 b}$ as a clear oil. $3.3 \mathrm{~g}, 50 \%$ yield. ${ }^{1} \mathrm{H} \mathrm{NMR}(300 \mathrm{MHz}$, $\left.\mathrm{CDCl}_{3}\right) \delta=4.06-3.95\left(\mathrm{~m}, 4 \mathrm{H}, \mathrm{OCH}_{2} \mathrm{CH}_{2} \mathrm{O}\right), 2.70\left(\mathrm{~s}, 2 \mathrm{H}, \mathrm{CH}_{2}\right), 1.83\left(\mathrm{t}, 2 \mathrm{H}, \mathrm{J}=7.3 \mathrm{~Hz}, \mathrm{CH}_{2}\right), 1.42-$ $1.18\left(\mathrm{~m}, 6 \mathrm{H}, \mathrm{J}=7.4 \mathrm{~Hz},\left(\mathrm{CH}_{2}\right)_{3}\right), 0.94\left(\mathrm{t}, 3 \mathrm{H}, \mathrm{J}=6.9 \mathrm{~Hz}, \mathrm{CH}_{3}\right) ;{ }^{13} \mathrm{C} \mathrm{NMR}\left(75 \mathrm{MHz}, \mathrm{CDCl}_{3}\right)$ $\delta=175.3,109.5,65.3,37.8,32.0,22.7,14.1 \mathrm{ppm}$. 


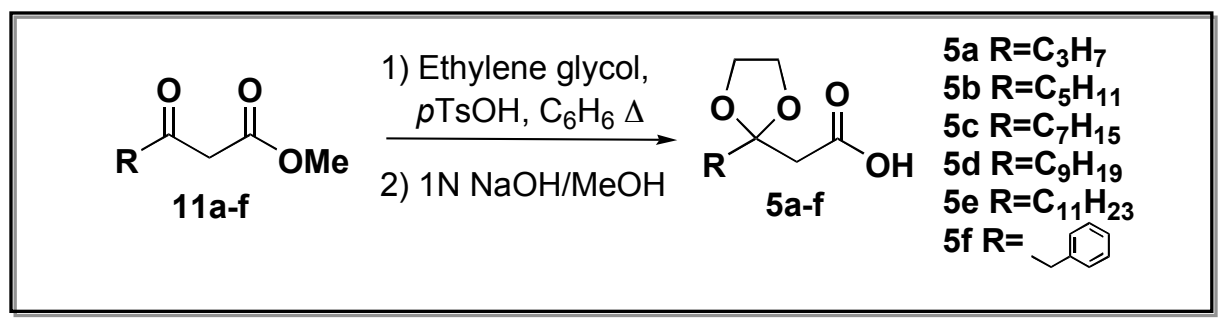

\section{Synthesis of natural and unnatural AHLs}

Representative $\boldsymbol{N}$-Fmoc-methionine resin loading protocol. Aminomethyl polystyrene resin $(1,5.2 \mathrm{~g}, 6 \mathrm{mmol})$ was pre-swelled in $40 \mathrm{~mL}$ of $\mathrm{CHCl}_{3}$ in a $100 \mathrm{~mL}$ round-bottom flask for $10 \mathrm{~min}$ at room temperature. In a separate flask, an activated solution of $N$-Fmoc-L-methionine $(2,6.7 \mathrm{~g}, 18 \mathrm{mmol}), 1$-hydroxybenzotriazole (HOBT $(2.8 \mathrm{~g}, 21 \mathrm{mmol})$ ), and $N, N$-diisopropylcarbodiimide (DIC, $3.8 \mathrm{~mL}, 24 \mathrm{mmol}$ ) was prepared in $50 \mathrm{~mL}$ of DMF. This activated solution was stirred for $10 \mathrm{~min}$ at room temperature and then added to the swelled resin. The reaction flask was equipped with a stir-bar and sealed with rubber septum that has been pierced to allow for the insertion of the Milestone fiber optic temperature probe (in a protective sheath). The reaction flask was placed into the Milestone Microsynth Labstation and irradiated for 10 min at $50{ }^{\circ} \mathrm{C}$ ( 3 min ramp to $50{ }^{\circ} \mathrm{C}$ with a max of $600 \mathrm{~W}$, hold $10 \mathrm{~min}$ at $50{ }^{\circ} \mathrm{C}$ with a max of $600 \mathrm{~W}$ ). The resin then was filtered and washed with $250 \mathrm{~mL}$ each of DMF, water, $\mathrm{EtOH}$, and $\mathrm{CH}_{2} \mathrm{Cl}_{2}$ and dried in vacuo. This coupling process was repeated $1 \mathrm{x}$ to yield $N$-Fmoc-L-methionine resin at 0.8-0.9 $\mathrm{mmol} / \mathrm{g}$ loading as quantified by UV absorbance.

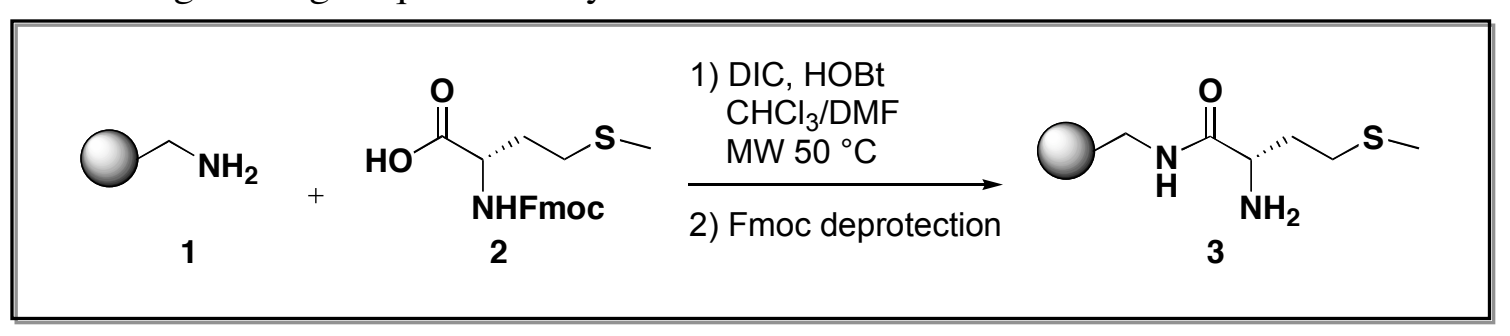

Representative UV Fmoc quantitation protocol. Approximately $20 \mathrm{mg}$ of $\mathrm{N}$-Fmoc-Lmethionine loaded resin was submersed in $3 \mathrm{~mL}$ of a $4 \%$ 1,8-diazabicyclo[5.4.0]undec-7-ene (DBU) solution in DMF and stirred for $30 \mathrm{~min}$ at room temperature. Thereafter, $100 \mu \mathrm{L}$ of the solution was removed and diluted to $3.0 \mathrm{~mL}$ in DMF. A $1.0 \mathrm{~mL}$ aliquot of this solution was withdrawn and the UV absorbance was read at $296 \mathrm{~nm}\left(\varepsilon_{296}=9500 \mathrm{M}^{-1} \mathrm{~cm}^{-1}\right)$ in a quartz cuvette. Loadings were calculated according to standard methods. ${ }^{4}$

Representative MW-assisted Fmoc-deprotection protocol. Approximately $300 \mathrm{mg}$ of $\mathrm{N}$ Fmoc-L-methionine loaded resin was placed in a $10 \mathrm{~mL}$ CEM MW vial with $4 \mathrm{~mL}$ of DMF and irradiated in the CEM Discover at $150{ }^{\circ} \mathrm{C}$ for $6 \min (300 \mathrm{~W}$ max. wattage). UV Fmocquantitation was performed as described above.

Alternate room temperature Fmoc deprotection protocol. $\mathrm{N}$-Fmoc-L-methionine loaded resin was placed into the appropriate size container and stirred with a solution of $20 \%$ piperidine/DMF 
solution for $30 \mathrm{~min}$. The solution was drained and the process was repeated. UV Fmocquantitation was performed as described above.

Representative synthesis of AHLs (7a-q). In a $10 \mathrm{~mL}$ CEM MW vial equipped with a stirbar, methionine resin 3 (300 mg, $0.295 \mathrm{mmol}$ ) was pre-swelled in $1.5 \mathrm{~mL}$ of $\mathrm{CHCl}_{3}$ for $5 \mathrm{~min}$ at room temperature. An activated solution of carboxylic acid 4 (1.03 mmol) and DIC (1.5 mmol) was prepared in a separate vial in $2 \mathrm{~mL}$ of DMF and stirred for $5 \mathrm{~min}$. The activated solution was added to the swelled resin, and the reaction mixture was subjected to MW irradiation for $10 \mathrm{~min}$ at $50{ }^{\circ} \mathrm{C}$ (ramp time $30 \mathrm{sec}$, hold for $10 \mathrm{~min}$ at $50{ }^{\circ} \mathrm{C}$, max. wattage $300 \mathrm{~W}$ ). The resin then was filtered and washed $2 \mathrm{X}$ with $50 \mathrm{~mL}$ each of $\mathrm{DMF}, \mathrm{H}_{2} \mathrm{O}, \mathrm{EtOH}$, and $\mathrm{CH}_{2} \mathrm{Cl}_{2}$ and dried in vacuo. To obtain the best yields, this process was repeated again. To affect compound cleavage, resin was treated with $7 \mathrm{~mL}$ of a 5:2 solution of $1.5 \mathrm{M} \mathrm{CNBr}$ in $\mathrm{CHCl}_{3}$ and $1 \%$ aqueous TFA solution and subjected to $\mathrm{MW}$ irradiation for $30 \mathrm{~min}$ at $60{ }^{\circ} \mathrm{C}$ (ramp time $60 \mathrm{sec}$, hold for $30 \mathrm{~min}$ at $60{ }^{\circ} \mathrm{C}$, max. wattage $300 \mathrm{~W}$ ). The AHL product was eluted from the resin with $5 \mathrm{~mL}$ of $\mathrm{CHCl}_{3}$, washed with water $(3 \times 10 \mathrm{~mL})$, dried over $\mathrm{MgSO}_{4}$, and concentrated in vacuo to yield the AHL as a white powder. Purities and yields for 7a-q reported in Table 1 of the manuscript and Table S-1.

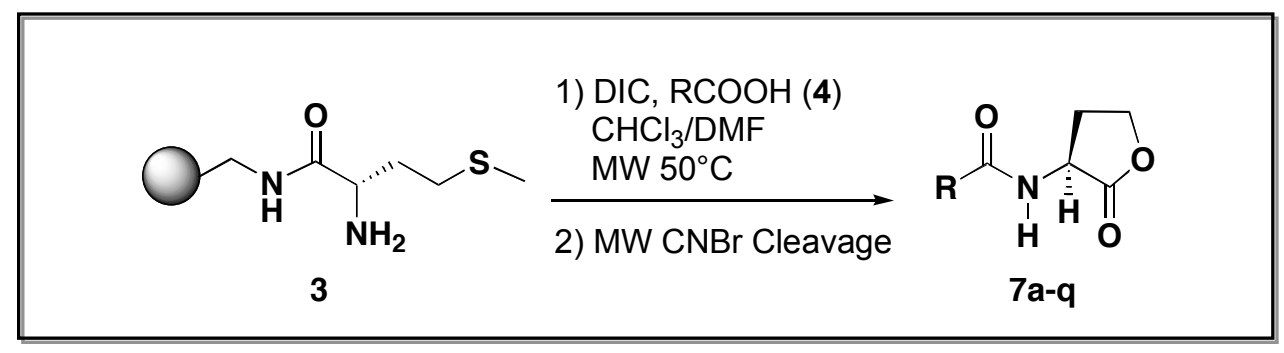

Representative synthesis of 3-oxo AHLs (8a-h). In a $10 \mathrm{~mL}$ CEM MW vial, methionine resin 3 (300 mg, $0.295 \mathrm{mmol}$ ) was pre-swelled in $1.5 \mathrm{~mL}$ of $\mathrm{CHCl}_{3}$ for $5 \mathrm{~min}$ at room temperature. An activated solution of 3,3-ethylenedioxocarboxylic acid 5 (1.03 mmol) and DIC $(1.5 \mathrm{mmol})$ was prepared in a separate vial in $2 \mathrm{~mL}$ of DMF and stirred for $5 \mathrm{~min}$. The activated solution was added to the swelled resin, and the reaction mixture was subjected to $\mathrm{MW}$ irradiation for $10 \mathrm{~min}$ at $50{ }^{\circ} \mathrm{C}$ (ramp time $30 \mathrm{sec}$, hold for $10 \mathrm{~min}$ at $50{ }^{\circ} \mathrm{C}$, max. wattage 300 W). The resin then was filtered and washed $2 \mathrm{x}$ with $50 \mathrm{~mL}$ each of DMF, $\mathrm{H}_{2} \mathrm{O}, \mathrm{EtOH}$, and $\mathrm{CH}_{2} \mathrm{Cl}_{2}$ and dried in vacuo. To obtain the best yields, this process was repeated again. To affect

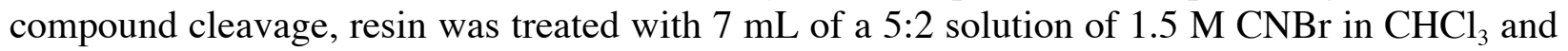
$1 \%$ aqueous TFA solution and subjected to $\mathrm{MW}$ irradiation for $30 \mathrm{~min}$ at $60{ }^{\circ} \mathrm{C}$ (ramp time 60 sec, hold for $30 \mathrm{~min}$ at $60{ }^{\circ} \mathrm{C}$, max. wattage $300 \mathrm{~W}$ ). AHL was eluted from the resin with $5 \mathrm{~mL}$ of $\mathrm{CHCl}_{3}$, washed with water $(3 \times 10 \mathrm{~mL})$, dried over $\mathrm{MgSO}_{4}$, and concentrated in vacuo. This material was stirred for $30 \mathrm{~min}$ in $5 \mathrm{~mL}$ of $50 \% \mathrm{TFA} / \mathrm{CH}_{2} \mathrm{Cl}_{2}$ to affect $\beta$-keto deprotection. The solution was washed with water $(2 \times 5 \mathrm{~mL})$, dried over $\mathrm{MgSO}_{4}$, and concentrated in vacuo to yield 3-oxo AHL product as a white powder. Purities and yields for $\mathbf{8 a - h}$ reported in Table 1 of manuscript and Table $\mathrm{S}-1$.

Alternative room temperature $M W$ cleavage protocol: To affect compound cleavage, resin was stirred at room temperature in $7 \mathrm{~mL}$ of a $5: 2$ solution of $1.5 \mathrm{M} \mathrm{CNBr}$ in $\mathrm{CHCl}_{3}$ and $50 \%$ aqueous TFA solution for $24 \mathrm{~h}$. AHL product was eluted from the resin with $5 \mathrm{~mL}$ of $\mathrm{CHCl}_{3}$, washed with water (3x10 mL), dried over $\mathrm{MgSO}_{4}$, and concentrated in vacuo to yield the 3-oxo AHL as a white powder. 


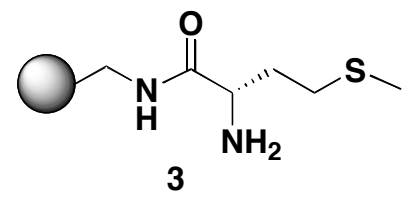

1) $\mathrm{DIC},(5)$ $\mathrm{CHCl}_{3} / \mathrm{DMF}$ $\mathrm{MW} 50^{\circ} \mathrm{C}$

2) MW CNBr Cleavage

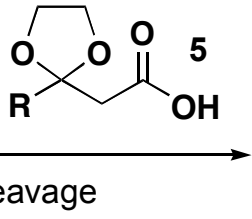

$\longrightarrow$

R<smiles>O=C([Hg])CC(=O)NC1CCOC1=O</smiles>

8a-h

Table S-1. Unnatural AHLs Synthesized via Scheme 1.

\begin{tabular}{|c|c|c|c|c|}
\hline compound & $\mathrm{R}^{1}$ or $\mathrm{R}^{2}$ & stereochemistry $^{a}$ & purity $[\%]^{b, c}$ & yield $[\%]^{d}$ \\
\hline $7 g$ & $\mathrm{C}_{6} \mathrm{H}_{13}$ & $L$ & 98 & 81 \\
\hline $7 \mathrm{~h}$ & & L & 94 & 61 \\
\hline $7 i$ & & D & 93 & 52 \\
\hline $7 \mathrm{j}$ & & L & $>93$ & 74 \\
\hline $7 k$ & & $\mathrm{~L}$ & 98 & 51 \\
\hline 71 & & D & 97 & 54 \\
\hline $7 m$ & & L & $>93$ & 64 \\
\hline $7 n$ & & L & $>93$ & 47 \\
\hline 70 & & L & 98 & 65 \\
\hline $7 p$ & & L & 93 & 76 \\
\hline $7 q$ & & L & 95 & 56 \\
\hline $7 r$ & & D & 95 & 62 \\
\hline $8 f$ & & $\mathrm{~L}$ & $>90$ & 59 \\
\hline $8 g$ & & D & $>90$ & 64 \\
\hline $8 h$ & $\mathrm{C}_{5} \mathrm{H}_{11}$ & $D$ & $>93$ & 54 \\
\hline
\end{tabular}

${ }^{a}$ Determined by the $\mathrm{N}-\mathrm{Fmoc}$ methionine (2) starting material ${ }^{b}$ Purities of 7g-h, 7I-m, and 7o-r determined by integration of GC spectra (flame ionization and MS detection). ${ }^{c}$ Purities of $\mathbf{7 i - k ,} \mathbf{7 n}$, and $\mathbf{8 f}-\mathbf{h}$ determined by ${ }^{1} \mathrm{H}$ NMR analyses. ${ }^{d}$ Isolated yield. 


\section{Characterization data for AHL derivatives}

$N$-butanoyl-L-homoserine lactone (7a): ${ }^{1} \mathrm{H}$ NMR $\left(300 \mathrm{MHz}, \mathrm{CDCl}_{3}\right) \delta=5.97(\mathrm{~s}, 1 \mathrm{H}, \mathrm{NH})$, 4.59 (ddd, 1H, J=5.9 Hz, CH-lac), 4.51 (td, 1H, J=1.1 Hz, CH-lac), 4.34 (ddd, 1H, J=5.9 Hz, CHlac), 2.93 (dddd, 1H, J=1.1 Hz, CH-lac), 2.27 (t, 2H, J=7.5 Hz, $\mathrm{CH}_{2}$ ), 2.17 (ddd, $1 \mathrm{H}, \mathrm{J}=1.7 \mathrm{~Hz}$, CH-lac), 1.29 (h, 2H, J=7.4 Hz, $\mathrm{CH}_{2}$ ), 0.99 (t, 3H, J=7.1 Hz, $\left.\mathrm{CH}_{3}\right) ;{ }^{13} \mathrm{C} \mathrm{NMR}\left(75 \mathrm{MHz}, \mathrm{CDCl}_{3}\right.$ ) $\delta=175.7,174.2,66.3,49.5,38.2,29.9,19.1,13.9$; GC-MS: expected $\mathrm{m} / \mathrm{z}=171$, observed $[\mathrm{M}+]=171 ;\left[\alpha_{\mathrm{D}}\right]=+14.8\left(\mathrm{c}=3.4 \mathrm{mg} / \mathrm{mL} ; \mathrm{CHCl}_{3}\right) ; \mathrm{IR}\left(\mathrm{cm}^{-1}\right): 3020,2401,1781,1515,1425,1216$, $929,757,670$.
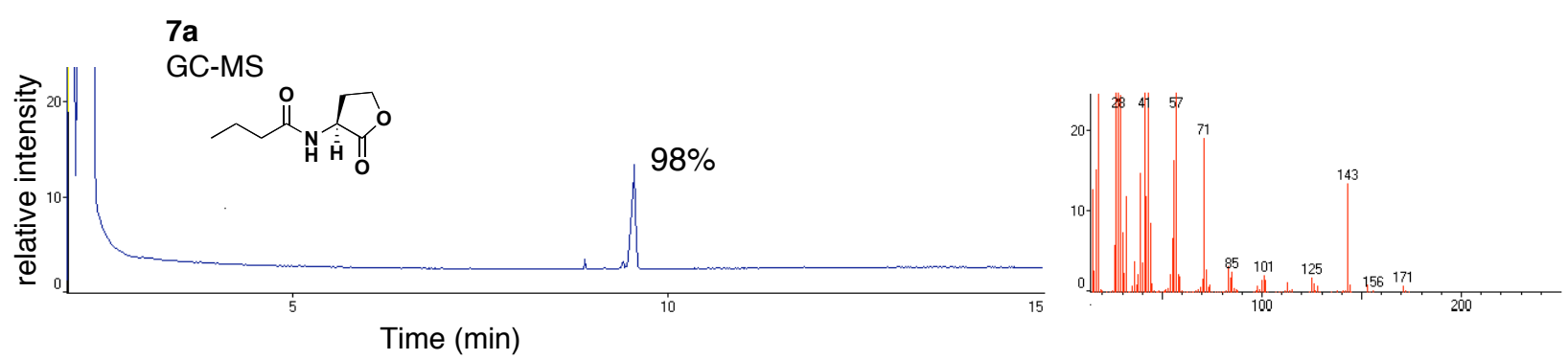

$N$-hexanoyl-L-homoserine lactone (7b): ${ }^{1} \mathrm{H} \mathrm{NMR}\left(300 \mathrm{MHz}, \mathrm{CDCl}_{3}\right) \delta=6.22(\mathrm{~s}, 1 \mathrm{H}, \mathrm{NH})$, 4.63 (ddd, 1H, J=6.1 Hz, CH-lac), 4.51 (td, 1H, J=1.0 Hz, CH-lac), 4.34 (ddd, 1H, J=5.9 Hz, CHlac), 2.89 (dddd, 1H, J=1.4 Hz, CH-lac), 2.28 (t, 2H, J=7.4 Hz, $\mathrm{CH}_{2}$ ), 2.20 (ddd, 1H, J=2.2 Hz, CH-lac), 1.71 (t, 2H, J=7.4 Hz, $\left.\mathrm{CH}_{2}\right), 1.34\left(\mathrm{~m}, 4 \mathrm{H},\left(\mathrm{CH}_{2}\right)_{2}\right), 0.93\left(\mathrm{t}, 3 \mathrm{H}, \mathrm{J}=7.1 \mathrm{~Hz}, \mathrm{CH}_{3}\right) ;{ }^{13} \mathrm{C}$ NMR (75 MHz, $\mathrm{CDCl}_{3}$ ) $\delta=175.9,174.1,66.4,49.4,36.4,31.6,30.8,25.4$, 22.6, 14.1; GC-MS: expected $\mathrm{m} / \mathrm{z}=199$, observed $[\mathrm{M}+]=199 ;\left[\alpha_{\mathrm{D}}\right]=+15.9\left(\mathrm{c}=3.4 \mathrm{mg} / \mathrm{mL} ; \mathrm{CHCl}_{3}\right) ; \mathrm{IR}\left(\mathrm{cm}^{-1}\right): 3689$, 3620, 3426, 3020, 2963, 2401, 1781, 1675, 1510, 1381, 1216, 1020, 929, 757, 669.
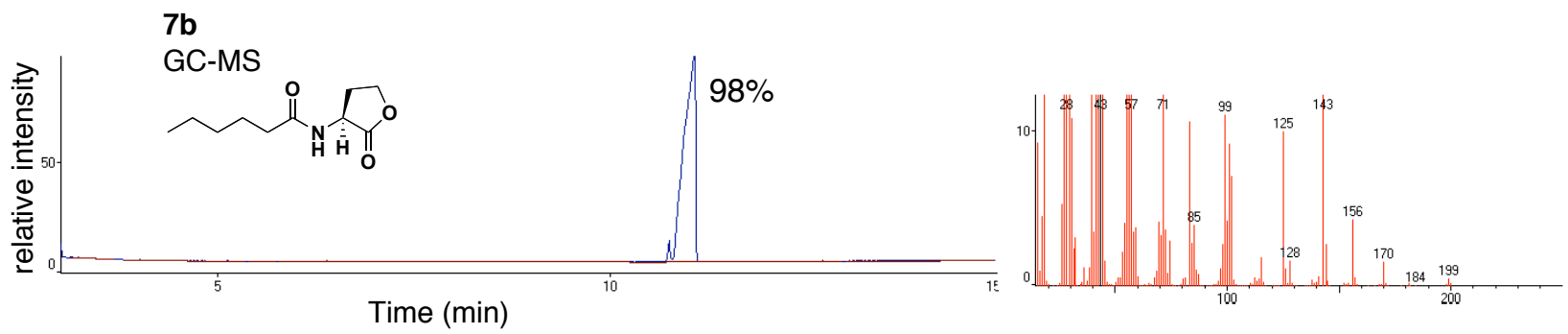

$\boldsymbol{N}$-octanoyl-L-homoserine lactone (7c): ${ }^{1} \mathrm{H}$ NMR $\left(300 \mathrm{MHz}, \mathrm{CDCl}_{3}\right) \delta=6.44(\mathrm{~s}, 1 \mathrm{H}, \mathrm{NH})$, 4.65 (ddd, 1H, J=6.5 Hz, CH-lac), 4.50 (t, 1H, J=9.2 Hz, CH-lac), 4.34 (ddd, 1H, J=2.3 Hz, CHlac), 2.85 (dddd, 1H, J=6.1 Hz, CH-lac), 2.28 (t, 2H, J=7.4 Hz, $\mathrm{CH}_{2}$ ), 2.22 (ddd, 1H, J=2.3 Hz, CH-lac), 1.67 (t, 2H, J=7.1 Hz, $\left.\mathrm{CH}_{2}\right), 1.30\left(\mathrm{~m}, 8 \mathrm{H},\left(\mathrm{CH}_{2}\right)_{4}\right), 0.91\left(\mathrm{t}, 3 \mathrm{H}, \mathrm{J}=6.3 \mathrm{~Hz}, \mathrm{CH}_{3}\right) ;{ }^{13} \mathrm{C}$ NMR $\left(75 \mathrm{MHz} \mathrm{CDCl}_{3}\right) \delta=175.5,173.7,65.9,48.9,35.9,31.4,30.1,29.0,28.8,25.2$, 22.4, 13.8; GC-MS: expected m/z=227, observed $[\mathrm{M}+]=227 ;\left[\alpha_{\mathrm{D}}\right]=+15.9\left(\mathrm{c}=3.4 \mathrm{mg} / \mathrm{mL} ; \mathrm{CHCl}_{3}\right) ; \mathrm{IR}\left(\mathrm{cm}^{-1}\right)$ : 3684, 3619, 3427, 3020, 2930, 2858, 2401, 1780, 1673, 1511, 1423, 1381, 1216, 1019, 929, 772, 669. 


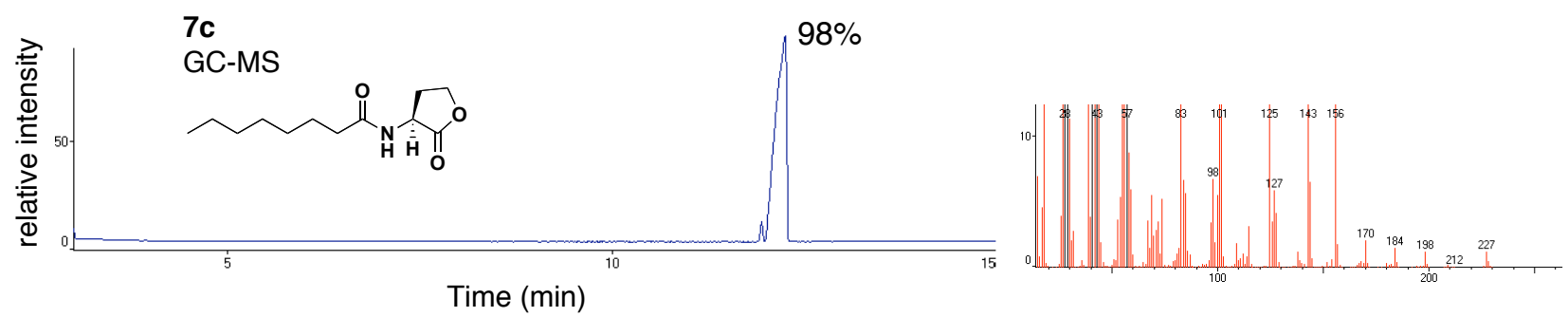

$\boldsymbol{N}$-decanoyl-L-homoserine lactone (7d): ${ }^{1} \mathrm{H} \mathrm{NMR}\left(300 \mathrm{MHz}, \mathrm{CDCl}_{3}\right) \delta=6.16(\mathrm{~s}, 1 \mathrm{H}, \mathrm{NH})$, 4.62 (ddd, 1H, J=6.0 Hz, CH-lac), 4.51 (td, 1H, J=1.0 Hz, CH-lac), 4.34 (ddd, 1H, J=5.9 Hz, CHlac), 2.90 (dddd, 1H, J=8.3 Hz, CH-lac), 2.28 (t, 2H, J=6.9 Hz, $\mathrm{CH}_{2}$ ), 2.15 (ddd, 1H, J=3.3 Hz, CH-lac), 1.70 (t, 2H, J=7.5 Hz, $\left.\mathrm{CH}_{2}\right), 1.30\left(\mathrm{~m}, 12 \mathrm{H},\left(\mathrm{CH}_{2}\right)_{6}\right), 0.91\left(\mathrm{t}, 3 \mathrm{H}, \mathrm{J}=6.6 \mathrm{~Hz}, \mathrm{CH}_{3}\right) ;{ }^{13} \mathrm{C}$ NMR (75 MHz, $\left.\mathrm{CDCl}_{3}\right) \delta=175.7,173.9,66.2$, 49.3, 36.3, 31.9, 30.7, 29.5, 29.4, 29.3, 25.5, 22.7, 14.2; GC-MS: expected m/z=255, observed $[\mathrm{M}+]=255 ;\left[\alpha_{\mathrm{D}}\right]=+15.5\left(\mathrm{c}=2.9 \mathrm{mg} / \mathrm{mL} ; \mathrm{CHCl}_{3}\right)$; IR $\left(\mathrm{cm}^{-1}\right)$ : 3684, 3620, 3427, 3020, 2928, 2857, 2401, 1780, 1673, 1511, 1423, 1381, 1216, 1019, 929, 772, 669.

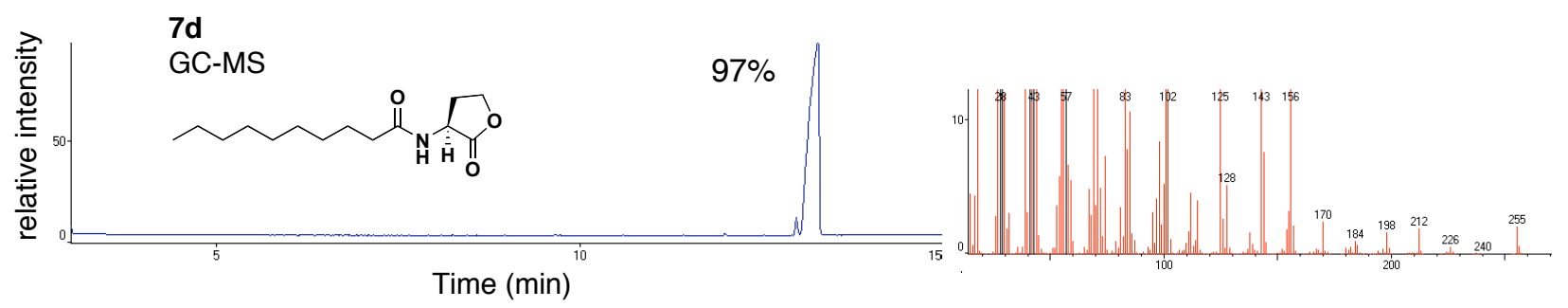

$\boldsymbol{N}$-dodecanoyl-L-homoserine lactone (7e): ${ }^{1} \mathrm{H}$ NMR $\left(300 \mathrm{MHz}, \mathrm{CDCl}_{3}\right) \delta=6.22(\mathrm{~s}, 1 \mathrm{H}$, $\mathrm{NH}$ ), 4.63 (ddd, 1H, J=6.1 Hz, CH-lac), 4.50 (t, 1H, J=9.1 Hz, CH-lac), 4.34 (ddd, 1H, J=5.9 Hz, CH-lac), 2.86 (dddd, 1H, J=5.9 Hz, CH-lac), 2.28 (t, 2H, J=6.9 Hz, $\mathrm{CH}_{2}$ ), 2.19 (ddd, 1H, J=2.9 $\mathrm{Hz}, \mathrm{CH}-\mathrm{lac}), 1.67$ (t, 2H, J=6.8 Hz, $\left.\mathrm{CH}_{2}\right), 1.30\left(\mathrm{~m}, 18 \mathrm{H},\left(\mathrm{CH}_{2}\right)_{9}\right), 0.91\left(\mathrm{t}, 3 \mathrm{H}, \mathrm{J}=6.5 \mathrm{~Hz}, \mathrm{CH}_{3}\right) ;{ }^{13} \mathrm{C}$ $\operatorname{NMR}\left(75 \mathrm{MHz}, \mathrm{CDCl}_{3}\right) \delta=176.1,174.3,66.6,49.7,36.7,32.4,31.0,30.1,29.9,29.7,29.6,25.9$, 23.2, 14.6; GC-MS: expected $\mathrm{m} / \mathrm{z}=283$, observed $[\mathrm{M}+]=283 ;\left[\alpha_{\mathrm{D}}\right]=+15.1(\mathrm{c}=3.5 \mathrm{mg} / \mathrm{mL}$; $\left.\mathrm{CHCl}_{3}\right)$; IR $\left(\mathrm{cm}^{-1}\right): 3684,3621,3426,3020,2928,2856,2401,1780,1673,1511,1381,1216$, $1019,929,760,669$.
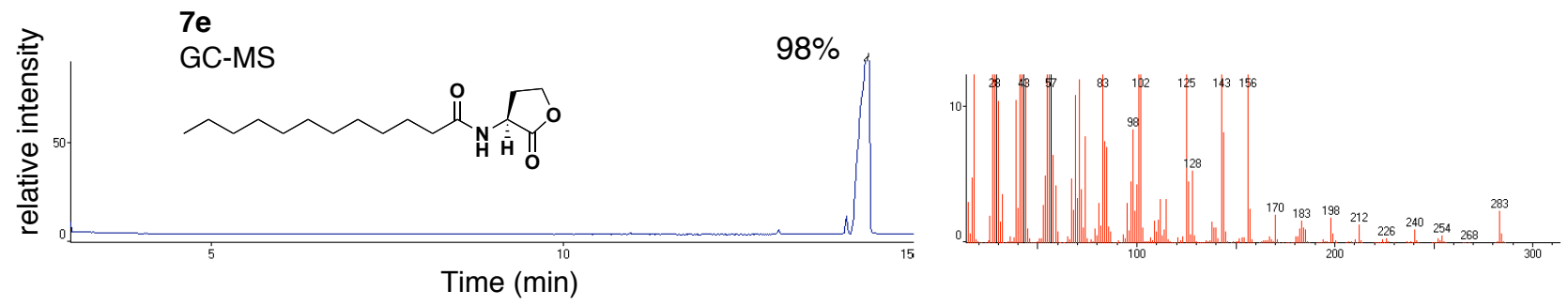
$\boldsymbol{N}$-hexadecanoyl-L-homoserine lactone (7f): ${ }^{1} \mathrm{H}$ NMR $\left(300 \mathrm{MHz}, \mathrm{CDCl}_{3}\right) \delta=6.03(\mathrm{~s}, 1 \mathrm{H}$, $\mathrm{NH}$ ), 4.59 (ddd, 1H, J=5.6 Hz, CH-lac), 4.50 (t, 1H, J=8.2 Hz, CH-lac), 4.33 (ddd, 1H, J=5.7 Hz, CH-lac), 2.92 (dddd, 1H, J=1.3 Hz, CH-lac), 2.28 (t, 2H, J=6.9 Hz, $\mathrm{CH}_{2}$ ), 2.20 (ddd, 1H, J=8.8 $\mathrm{Hz}, \mathrm{CH}-\mathrm{lac}), 1.69$ (t, 2H, J=7.1 Hz, $\left.\mathrm{CH}_{2}\right), 1.31\left(\mathrm{~m}, 24 \mathrm{H},\left(\mathrm{CH}_{2}\right)_{12}\right), 0.91$ (t, 3H, J=6.4 Hz, CH$)_{3}$; ${ }^{13} \mathrm{C}$ NMR $\left(75 \mathrm{MHz}, \mathrm{CDCl}_{3}\right) \delta=175.8,174.0,66.4,49.6,36.5,32.2,31.0,30.0,29.7,29.6,29.5$, 25.7, 23.0, 14.4; GC-MS: expected $\mathrm{m} / \mathrm{z}=339$, observed $[\mathrm{M}+]=339 ;\left[\alpha_{\mathrm{D}}\right]=+14.9(\mathrm{c}=2.4 \mathrm{mg} / \mathrm{mL}$; $\left.\mathrm{CHCl}_{3}\right)$; IR $\left(\mathrm{cm}^{-1}\right): 3684,3621,3426,3020,2928,2855,2401,1781,1675,1513,1424,1381$, 1216.

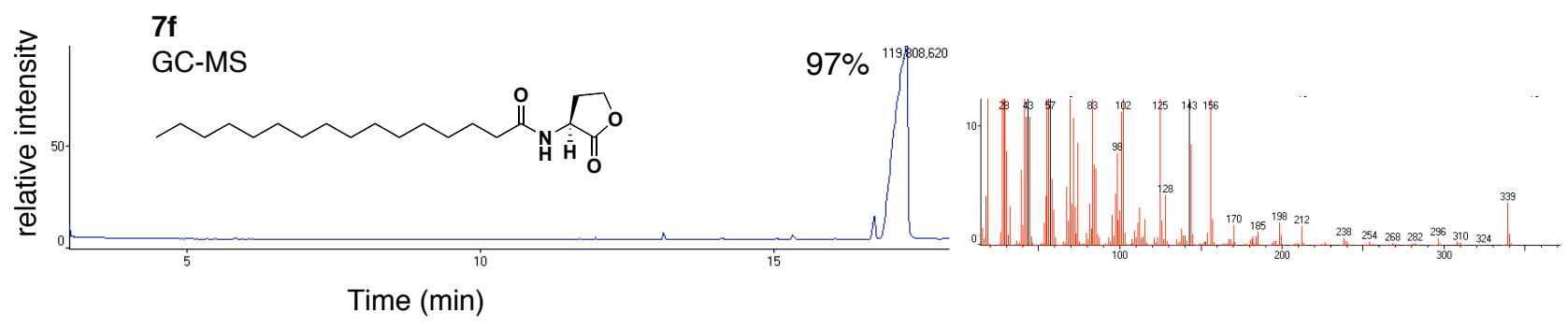

$\boldsymbol{N}$-heptanoyl-L-homoserine lactone (7g): ${ }^{1} \mathrm{H}$ NMR $\left(300 \mathrm{MHz}, \mathrm{CDCl}_{3}\right) \delta=6.28(\mathrm{~s}, 1 \mathrm{H}, \mathrm{NH})$, 4.64 (ddd, 1H, J=6.4 Hz, CH-lac), 4.50 (td, 1H, J=1.2 Hz, CH-lac), 4.34 (ddd, 1H, J=5.8 Hz, CHlac), 2.87 (dddd, 1H, J=8.4 Hz, CH-lac), 2.28 (t, 2H, J=6.7 Hz, $\mathrm{CH}_{2}$ ), 2.20 (ddd, 1H, J=2.5 Hz, CH-lac), 1.70 (t, 2H, J=7.8 Hz, $\left.\mathrm{CH}_{2}\right), 1.38\left(\mathrm{~m}, 6 \mathrm{H},\left(\mathrm{CH}_{2}\right)_{3}\right), 0.91\left(\mathrm{t}, 3 \mathrm{H}, \mathrm{J}=6.7 \mathrm{~Hz}, \mathrm{CH}_{3}\right) ;{ }^{13} \mathrm{C}$ NMR $\left(75 \mathrm{MHz}, \mathrm{CDCl}_{3}\right) \delta=175.5,173.6,65.9,49.0,36.0,31.3,30.3,28.7,25.2,22.3$, 13.8; GCMS: expected $\mathrm{m} / \mathrm{z}=213$, observed $[\mathrm{M}+]=213 ;\left[\alpha_{\mathrm{D}}\right]=+12.6\left(\mathrm{c}=1.9 \mathrm{mg} / \mathrm{mL} ; \mathrm{CHCl}_{3}\right) ; \mathrm{IR}\left(\mathrm{cm}^{-1}\right)$ : 3685, 3621, 3427, 3020, 2931, 2401, 1780, 1674, 1510, 1423, 1381, 1216.

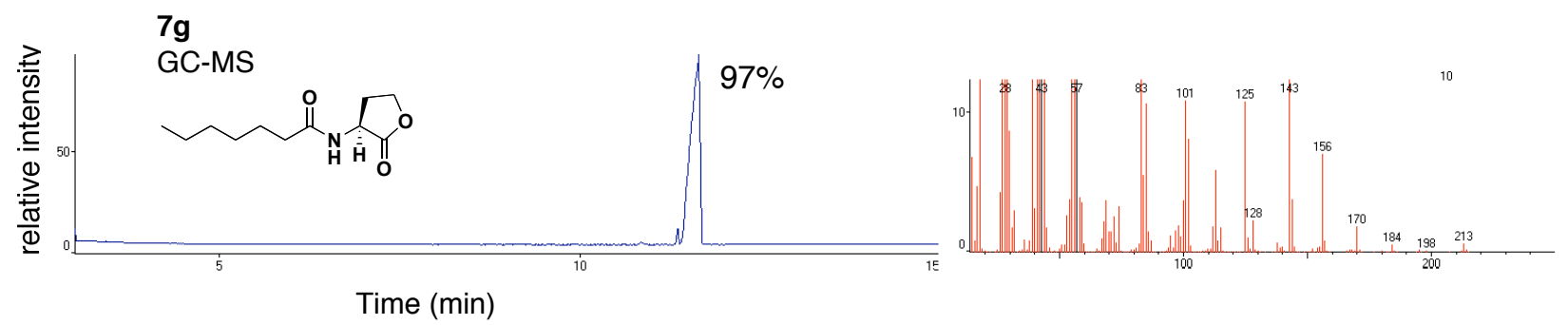

$N$-(indole-3-butanoyl)-L-homoserine lactone (7h): ${ }^{1} \mathrm{H} \mathrm{NMR}\left(300 \mathrm{MHz}, \mathrm{CDCl}_{3}\right) \delta=8.08$ (s, 1H, NH-indole), 7.59 (d, 1H, J=7.6 Hz, CH-Ar), 7.35 (d, 1H, J=7.1 Hz, CH-Ar), 7.20 (td, 1H, $\mathrm{J}=1.2 \mathrm{~Hz}, \mathrm{CH}-\mathrm{Ar}$ ), 7.12 (td, 1H, J=1.2 Hz, CH-Ar), 6.97 (d, 1H J=2.3 Hz, CH-Ar), 6.05 (d, 1H, $\mathrm{J}=5.8 \mathrm{~Hz}, \mathrm{NH}$ ), 4.54 (ddd, 1H, J=6.3 Hz, CH-lac), 4.43 (td, 1H, J=0.9 Hz, CH-lac), 4.26 (ddd, $1 \mathrm{H}, \mathrm{J}=6.0 \mathrm{~Hz}, \mathrm{CH}-\mathrm{lac}$ ), 2.82 (t, 2H, J=7.3 Hz, $\mathrm{CH}_{2}$ ), 2.76 (m, 1H, CH-lac), 2.28 (t, 2H, J=7.7 Hz, $\mathrm{CH}_{2}$ ), 2.10 (m, 3H, $\left.\mathrm{CH}_{2}+\mathrm{CH}-\mathrm{lac}\right) ;{ }^{13} \mathrm{C} \mathrm{NMR}\left(75 \mathrm{MHz}, \mathrm{CDCl}_{3}\right) \delta=122.2,121.9,119.5,119.1$, 115.6, 111.3, 66.2, 49.4, 35.7, 30.7, 25.8, 24.6; GC-MS: expected m/z=286, observed [M+]=286; $\left[\alpha_{\mathrm{D}}\right]=+14.2\left(\mathrm{c}=2.6 \mathrm{mg} / \mathrm{mL} ; \mathrm{CHCl}_{3}\right) ; \mathrm{IR}\left(\mathrm{cm}^{-1}\right): 3684,3620,3480,3426,3020,2977,2401,2362$, 2254, 1780, 1674, 1603, 1514, 1217. 


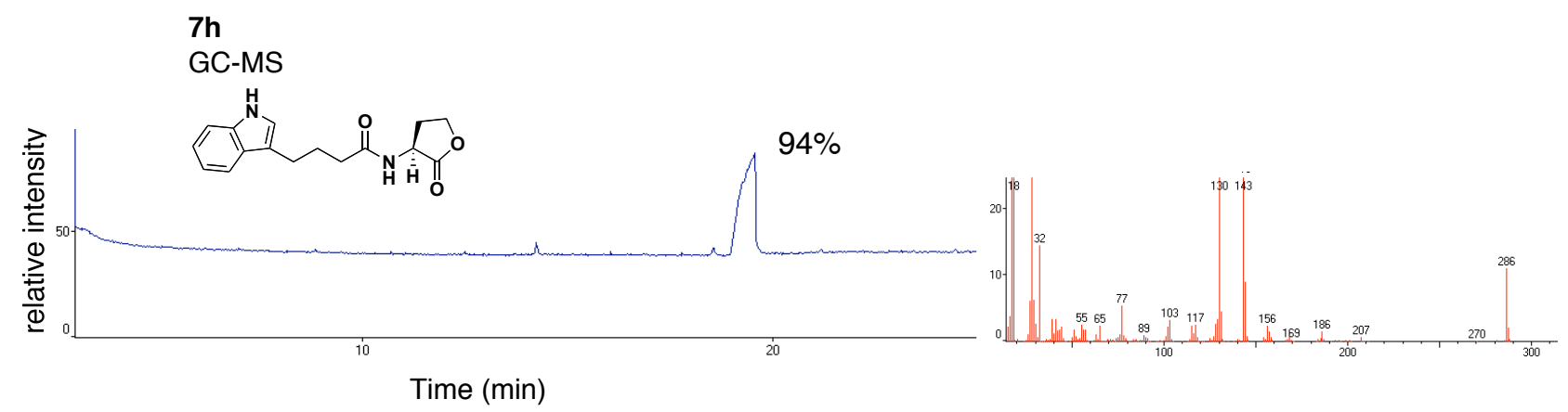

$\boldsymbol{N}$-(indole-3-butanoyl)-D-homoserine lactone (7i): ${ }^{1} \mathrm{H} \mathrm{NMR}\left(300 \mathrm{MHz}, \mathrm{CDCl}_{3}\right) \delta=7.99$ (s, 1H, NH), 7.61 (d, 1H, J=0.6 Hz, CH-Ar), 7.37 (d, 1H, J=0.4 Hz, CH-Ar), 7.26 (m, 2H, CH-Ar), 7.01 (d, 1H, J=2.1 Hz, CH-Ar), 5.90 (d, 1H, J=4.4 Hz, NH), 4.55 (ddd, 1H, J=5.9 Hz, CH-lac), 4.46 (td, 1H, J=8.3 Hz, CH-lac) 4.29 (ddd, 1H, J=5.9 Hz, CH-lac), 2.85 (m, 3H), 2.32 (m, 2H), $2.17(\mathrm{~m}, 3 \mathrm{H}) ;{ }^{13} \mathrm{C}$ NMR $\left(75 \mathrm{MHz}, \mathrm{CDCl}_{3}\right) \delta=122.2,121.8,119.5,111.3,66.3,49.4,35.7,30.7$, 25.8, 24.6; GC-MS: expected $\mathrm{m} / \mathrm{z}=286$, observed $[\mathrm{M}+]=286 ;\left[\alpha_{\mathrm{D}}\right]=-11.6(\mathrm{c}=1.95 \mathrm{mg} / \mathrm{mL}$; $\left.\mathrm{CHCl}_{3}\right)$; IR $\left(\mathrm{cm}^{-1}\right): 3359,2921,2692,2358,1771,1648,1558,1220,1019$.

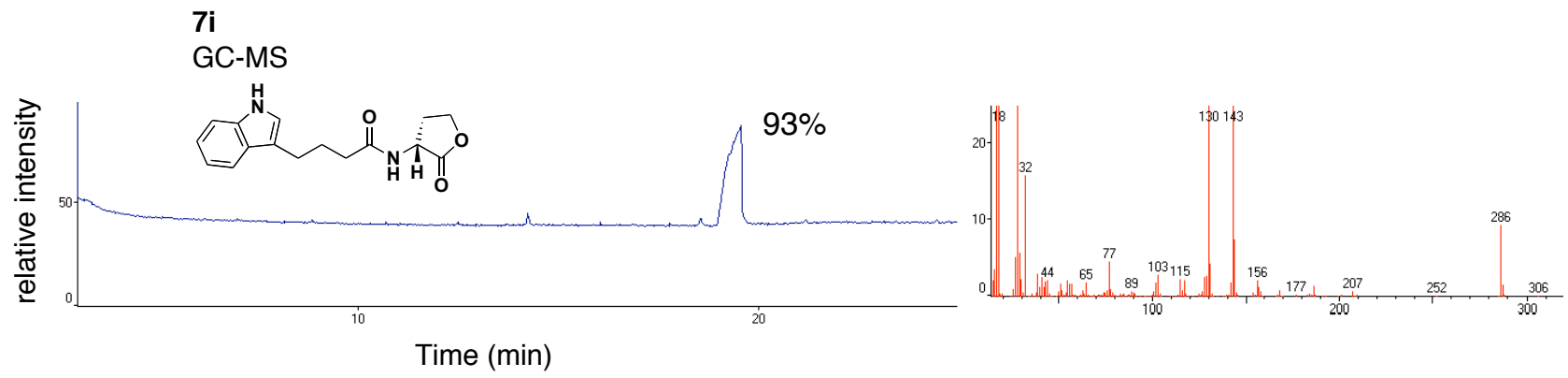

$\boldsymbol{N}$-Boc-(4-aminomethyl)- $\boldsymbol{N}$-benzoyl-L-homoserine lactone (7j): ${ }^{1} \mathrm{H}$ NMR $(300 \mathrm{MHz}$, $\left.\mathrm{CDCl}_{3}\right) \delta=7.78(\mathrm{~d}, 2 \mathrm{H}, \mathrm{Ar}-\mathrm{H}), 7.35$ (d, 2H, Ar-H), 6.02 (d, 1H, NH), 4.98 (s, 1H, NH), 4.79 (ddd, $1 \mathrm{H}, \mathrm{J}=6.0 \mathrm{~Hz}, \mathrm{CH}-\mathrm{lac}), 4.57$ (td, 1H, J=0.9 Hz, CH-lac), 4.40 (m, 3H, J=8.7 Hz, $\left.\mathrm{CH}_{2}+\mathrm{CH}-\mathrm{lac}\right)$ 3.00 (dddd, 1H, J=1.2 Hz, CH-lac), 2.35 (ddd, 1H, J=8.8 Hz, CH-lac), 1.47 (s, 9H, BocCH ${ }_{3}$ ); ${ }^{13} \mathrm{C}$ NMR (75 MHz, $\mathrm{CDCl}_{3}$ ) $\delta=131.7,127.3,66.1,49.6,30.4,28.2 ; \mathrm{MS}(\mathrm{ESI}):$ expected m/z=334, observed $[\mathrm{M}+\mathrm{Na}]=357 ;\left[\alpha_{\mathrm{D}}\right]=+21.6\left(\mathrm{c}=2.7 \mathrm{mg} / \mathrm{mL} ; \mathrm{CHCl}_{3}\right) ; \mathrm{IR}\left(\mathrm{cm}^{-1}\right): 3621,3453,3020,2401$, $1780,1692,1527,1216$.

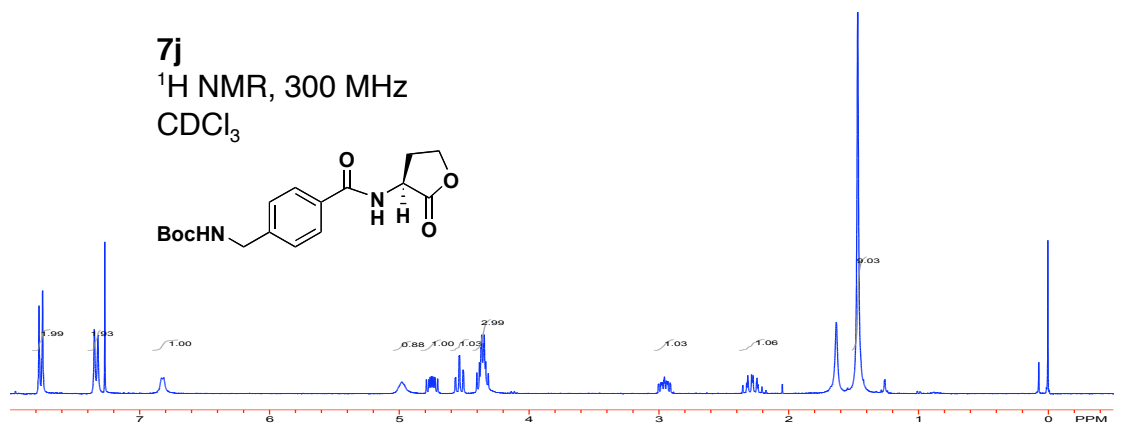


$\boldsymbol{N}$-(2-cyclopentene-1-acetanoyl)-L-homoserine lactone (7k): ${ }^{1} \mathrm{H}$ NMR (300 $\mathrm{MHz}, \mathrm{CDCl}_{3}$ ) $\delta=6.01(\mathrm{~d}, 1 \mathrm{H}, \mathrm{NH}), 5.81(\mathrm{~m}, 1 \mathrm{H}, \mathrm{CH}$-vinyl), 5.69 (m, 1H, CH-vinyl), 4.57 (ddd, 1H, J=3.0 Hz, CH-lac), 4.5 (td, 1H, J=9.5 Hz, CH-lac), 4.33 (ddd, 1H, J=6.0 Hz, CH-lac), 3.15 (m, 1H, J=2.6 $\mathrm{Hz}, \mathrm{CH}$ ), 2.91 (ddd, 1H, J=1.2 Hz, CH-lac) 2.39-2.09 (m, 6H), 1.52 (ddd, 1H, J=5.0 Hz, CHlac); ${ }^{13} \mathrm{C}$ NMR (75 MHz, $\mathrm{CDCl}_{3}$ ) $\delta=175.6,173.0,133.7,132.1,66.3,49.5,42.6,42.6,42.4,32.1$, 30.9, 29.8, 29.7; GC-MS: expected $\mathrm{m} / \mathrm{z}=209$, observed $[\mathrm{M}+]=209 ;\left[\alpha_{\mathrm{D}}\right]=+10.8(\mathrm{c}=2.6 \mathrm{mg} / \mathrm{mL}$; $\left.\mathrm{CHCl}_{3}\right)$; IR (cm $\left.{ }^{-1}\right): 3311,2923,2851,1775,1643,1546,1173,1016$.

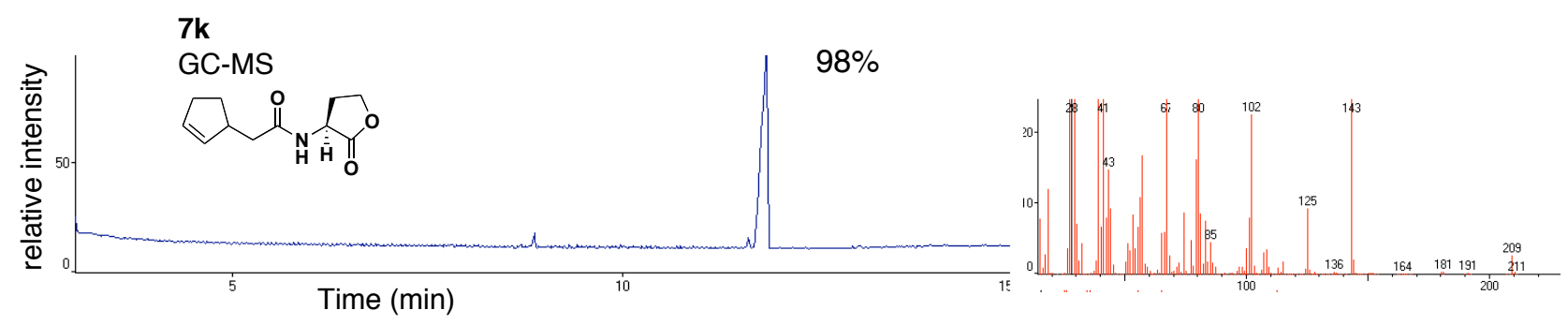

$\mathrm{N}$-(2-cyclopentene-1-acetanoyl)-D-homoserine lactone (7l): ${ }^{1} \mathrm{H} \mathrm{NMR}$ (300 $\mathrm{MHz}, \mathrm{CDCl}_{3}$ ) $\delta=6.07(\mathrm{~s}, 1 \mathrm{H}, \mathrm{NH}), 5.81-5.70(\mathrm{~m}, 1 \mathrm{H}, \mathrm{CH}$-vinyl), 5.69-5.66 (m, 1H, CH-vinyl), 4.60 (ddd, 1H, $\mathrm{J}=2.9 \mathrm{~Hz}, \mathrm{CH}-\mathrm{lac}$ ), 4.47 (td, 1H, J=8.3 Hz, CH-lac), 4.33 (ddd, 1H, J=6.0 Hz, CH-lac), 3.15-3.10 (m, 1H), 2.91 (ddd, 1H, J=1.3 Hz, CH-lac) 2.40-2.08 (m, 6H), 1.54-1.43 (m, 1H, CH-lac); ${ }^{13} \mathrm{C}$ NMR $\left(75 \mathrm{MHz}, \mathrm{CDCl}_{3}\right) \delta=173.0,033.8,133.7,132.1,132.0,66.3,49.5,42.6,42.6,42.4,32.0$, 30.8, 29.7; GC-MS: expected $\mathrm{m} / \mathrm{z}=209$, observed $[\mathrm{M}+]=209 ;\left[\alpha_{\mathrm{D}}\right]=-12.9(\mathrm{c}=2.7 \mathrm{mg} / \mathrm{mL}$; $\left.\mathrm{CHCl}_{3}\right)$; IR $\left(\mathrm{cm}^{-1}\right): 3310,2923,2851,2385,1775,1643,1546,1173,1016$.
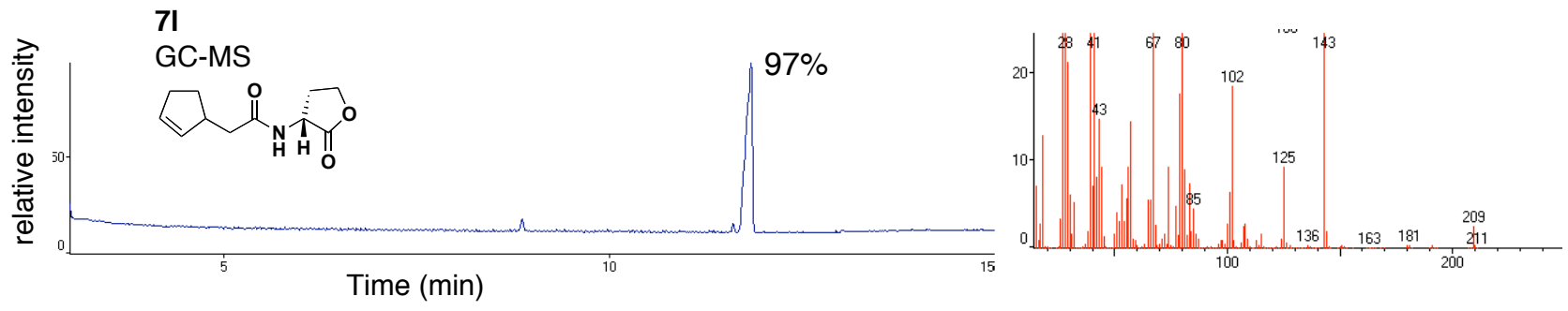

$\boldsymbol{N}$-Boc-aminocapranoyl-L-homoserine lactone (7m): ${ }^{1} \mathrm{H} \mathrm{NMR}\left(300 \mathrm{MHz}, \mathrm{CDCl}_{3}\right) \delta=6.50$ (d, 1H, NH), 4.65 (m, 2H, CH-lac, NH), 4.49 (td, 1H, J=9.0 Hz, CH-lac), 4.32 (ddd, 1H, J=6.1 $\mathrm{Hz}, \mathrm{CH}-\mathrm{lac}$ ), 3.11 (q, 2H, J=6.3 Hz, $\mathrm{CH}_{2}$ ), 2.79 (ddd, 1H, J=4.5 Hz, CH-lac), 2.28 (t, 2H, J=7.5 $\mathrm{Hz}, \mathrm{CH}_{2}$ ), 2.17 (ddd, 1H, J=6.8 Hz, CH-lac) 1.69 (p, 2H, J=7.4 Hz, $\mathrm{CH}_{2}$ ), $1.52(\mathrm{~m}, 12 \mathrm{H}) ;{ }^{13} \mathrm{C}$ NMR $\left(75 \mathrm{MHz}, \mathrm{CDCl}_{3}\right) \delta=175.8,173.7,156.2,66.2,49.2,40.5,36.0,31.1,30.3,29.9$, 28.6, 26.4, 25.1, 16.5; GC-MS: expected $\mathrm{m} / \mathrm{z}=314$, observed $[\mathrm{M}+\mathrm{Na}]=337 ;\left[\alpha_{\mathrm{D}}\right]=+5.7(\mathrm{c}=2.1 \mathrm{mg} / \mathrm{mL}$; $\left.\mathrm{CHCl}_{3}\right) ; \mathrm{IR}\left(\mathrm{cm}^{-1}\right): 3684,3455,3020,2401,1781,1693,1511,1216$. 


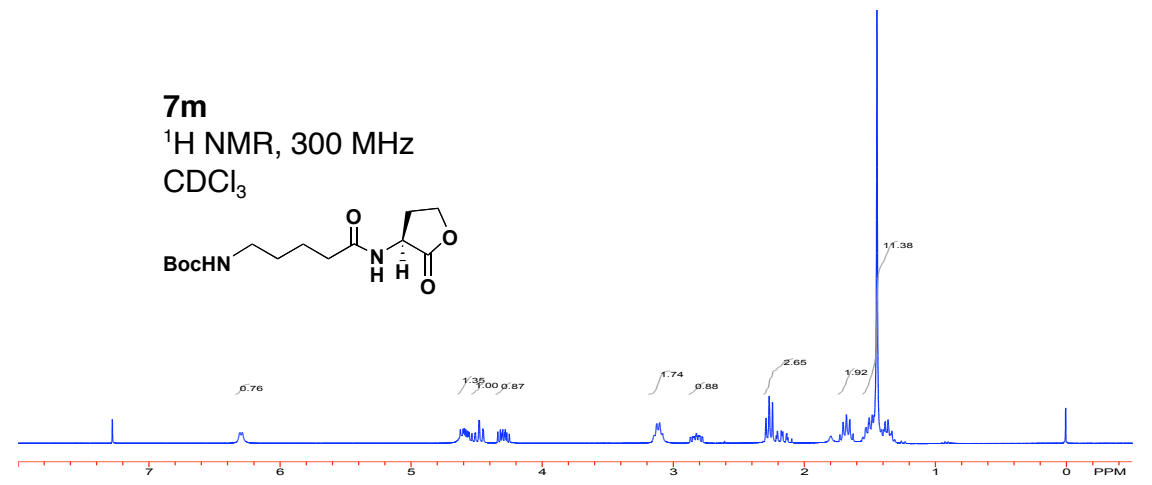

$N$-monoethyl fumaroyl-L-homoserine lactone (7n): ${ }^{1} \mathrm{H} \mathrm{NMR}\left(300 \mathrm{MHz}, \mathrm{CDCl}_{3}\right) \delta=7.0(\mathrm{~d}$, 2H, Ar-H), 6.87 (d, 2H, Ar-H), 4.72 (ddd, 1H, J=6.3 Hz, CH-lac), 4.54 (td, 1H, J=1.3 Hz, CHlac), 4.37 (ddd, 1H, J=6.0 Hz, CH-lac), 4.29 (q, 2H, J=7.1 Hz, $\mathrm{CH}_{2}$ ), 2.91 (ddd, 1H, J=1.4 Hz, CH-lac), 2.31 (ddd, $1 \mathrm{H}, \mathrm{J}=8.7 \mathrm{~Hz}, \mathrm{CH}-\mathrm{lac}) 1.47$ (s, 2H, $\mathrm{CH}_{2}$ ), 1.34 (t, 3H, J=7.1 Hz, $\mathrm{CH}_{3}$ ); ${ }^{13} \mathrm{C}$ NMR $\left(75 \mathrm{MHz}, \mathrm{CDCl}_{3}\right) \delta=175.2,165.5,164.4,135.1,131.8,66.4,61.6,49.7,30.4,28.5,14.3$; GC-MS: expected m/z=227, observed $[\mathrm{M}+]=227 ;\left[\alpha_{\mathrm{D}}\right]=+4.7\left(\mathrm{c}=2.8 \mathrm{mg} / \mathrm{mL} ; \mathrm{CHCl}_{3}\right) ; \mathrm{IR}\left(\mathrm{cm}^{-1}\right)$ : 3316, 2923, 1778, 1712, 1645, 1549, 1166.

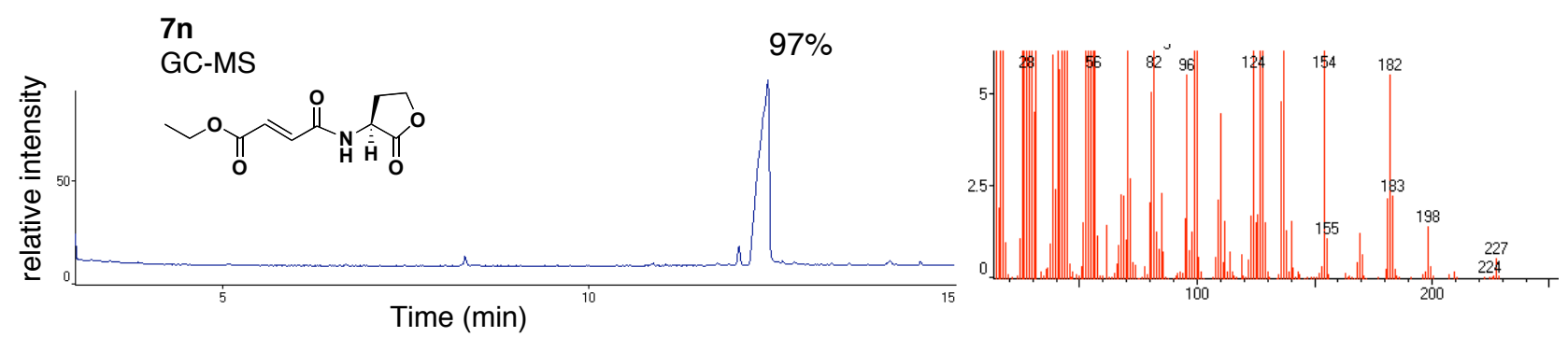

$\boldsymbol{N}$-(4-bromophenylacetanoyl)-L-homoserine lactone (7o): ${ }^{1} \mathrm{H}$ NMR (300 $\mathrm{MHz}, \mathrm{CDCl}_{3}$ ) $\delta=7.49$ (d, 2H, J=2.7 Hz, CH-Ar), 7.17 (d, 2H, J=2.7 Hz, CH-Ar), 6.02 (s, 1H, NH), 4.58 (ddd, 1H, J=6.2 Hz, CH-lac), 4.45 (td, 1H, J=1.2 Hz, CH-lac), 4.33 (ddd, 1H, J=5.9 Hz, CH-lac), 3.59 (s, 2H, $\mathrm{CH}_{2}$ ), 2.87 (ddd, 2H, J=1.4 Hz, CH-lac), 2.19 (dd, 1H, J=8.9 Hz, CH-lac); ${ }^{13} \mathrm{C}$ NMR (75 $\mathrm{MHz}, \mathrm{CDCl}_{3}$ ) $\delta=132.8,131.9,130.9,65.8,49.2$, 30.1; GC-MS: expected m/z=297, observed $[\mathrm{M}+]=297 ;\left[\alpha_{\mathrm{D}}\right]=+3.8\left(\mathrm{c}=2.55 \mathrm{mg} / \mathrm{mL} ; \mathrm{CHCl}_{3}\right) ; \mathrm{IR}\left(\mathrm{cm}^{-1}\right): 3419,3020,2401,1782,1672,1216$.

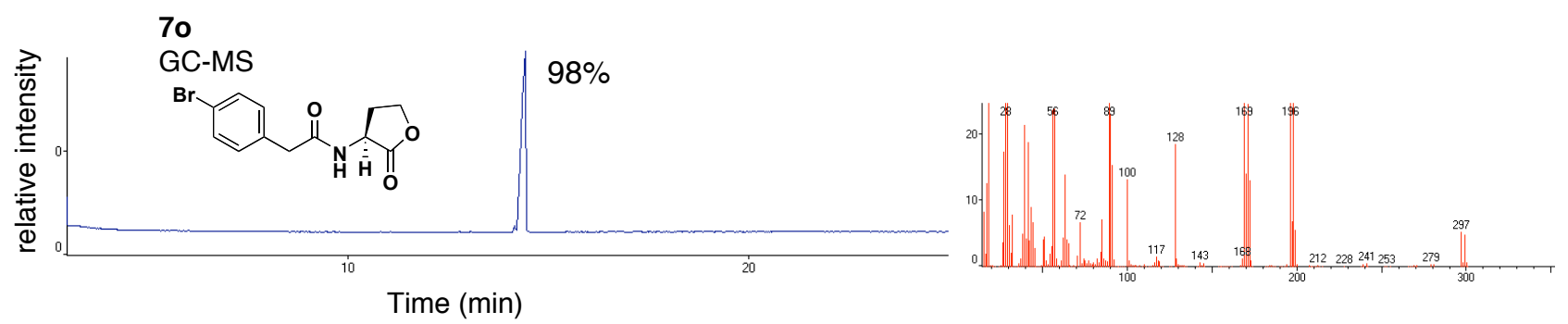


$\boldsymbol{N}$-(trans-cinamoyl)-L-homoserine lactone (7p): ${ }^{1} \mathrm{H}$ NMR $\left(300 \mathrm{MHz}, \mathrm{CDCl}_{3}\right) \delta=7.66(\mathrm{~d}$, 2H, Ar-H), 7.48 (m, 2H, Ar-H), 7.36 (m, 3H, Ar-H), 6.51 (d, 1H, J=5.9 Hz, NH), 6.49 (d, 1H, $\mathrm{J}=15.7 \mathrm{~Hz}, \mathrm{H}$-vinyl), 4.78 (ddd, 1H, J=6.4 Hz, CH-lac), 4.53 (td, 1H, J=8.9 Hz, CH-lac), 4.37 (ddd, 1H, J=5.9 Hz, CH-lac) 2.92 (ddd, 1H, J=1.0 Hz, CH-lac), 2.32 (td, 1H, J=8.9 Hz, CH-lac); ${ }^{13} \mathrm{C}$ NMR $\left(75 \mathrm{MHz}, \mathrm{CDCl}_{3}\right.$ ) $\delta=176.0,166.6,142.6,134.6,130.2,129.1,128.2,119.5,66.5,49.7$, 30.7; GC-MS: expected m/z=231, observed $[\mathrm{M}+]=231 ;\left[\alpha_{\mathrm{D}}\right]=+30.2\left(\mathrm{c}=2.45 \mathrm{mg} / \mathrm{mL} ; \mathrm{CHCl}_{3}\right)$; IR $\left(\mathrm{cm}^{-1}\right): 3312,2923,1774,1644,1547,1173,1016$.
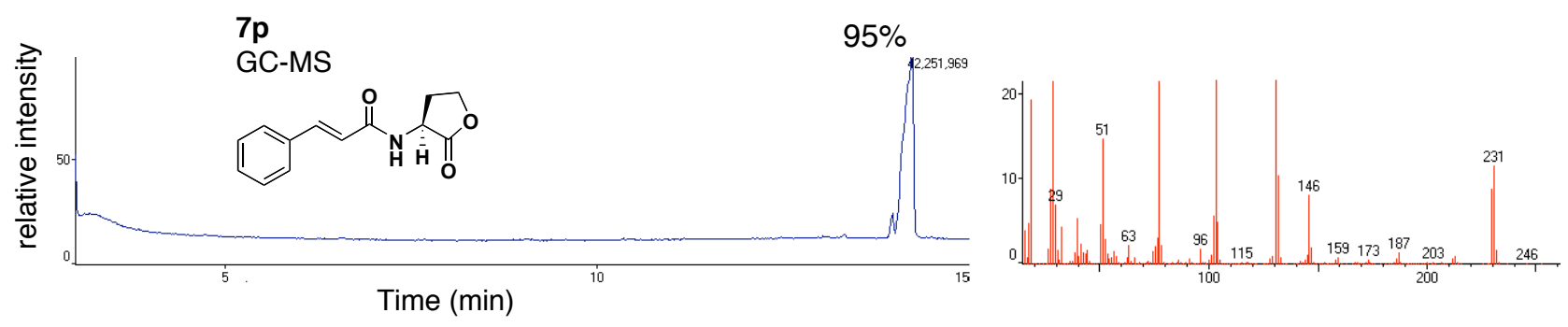

$\boldsymbol{N}$-(4-phenylbutanoyl)-L-homoserine lactone (7q): ${ }^{1} \mathrm{H} \mathrm{NMR}\left(300 \mathrm{MHz}, \mathrm{CDCl}_{3}\right) \delta=7.31(\mathrm{~m}$, 2H, Ar-H), 7.21 (m, 3H, Ar-H), 6.13 (d, 1H, J=5.3 Hz, NH), 4.59 (ddd, 1H, J=6.2 Hz, CH-lac), 4.47 (td, 1H, J=1.0 Hz, CH-lac), 4.30 (ddd, 1H, J=5.7 Hz, CH-lac), 2.85 (ddd, 1H, J=1.1 Hz, CHlac), 2.68 (t, 2H, J=7.3 Hz, $\mathrm{CH}_{2}$ ), 2.36 (t, 2H, J=6.7 Hz, $\mathrm{CH}_{2}$ ), 2.18 (d, 1H, J=3.2 Hz, CH-lac), 2.04 (p, 2H, J=7.4 Hz, $\left.\mathrm{CH}_{2}\right) ;{ }^{13} \mathrm{C}$ NMR $\left(75 \mathrm{MHz} \mathrm{CDCl}_{3}\right) \delta=175.7,173.5,167.7,141.5,128.7$, 128.6, 126.2, 115.0, 66.3, 49.4, 35.5, 35.3, 30.7, 27.0; GC-MS: expected m/z=247, observed $[\mathrm{M}+]=247 ;\left[\alpha_{\mathrm{D}}\right]=+27.9\left(\mathrm{c}=6.7 \mathrm{mg} / \mathrm{mL} ; \mathrm{CHCl}_{3}\right) ; \mathrm{IR}\left(\mathrm{cm}^{-1}\right): 3314,2935,2358,2331,1771$, $1652,1447,1173$.

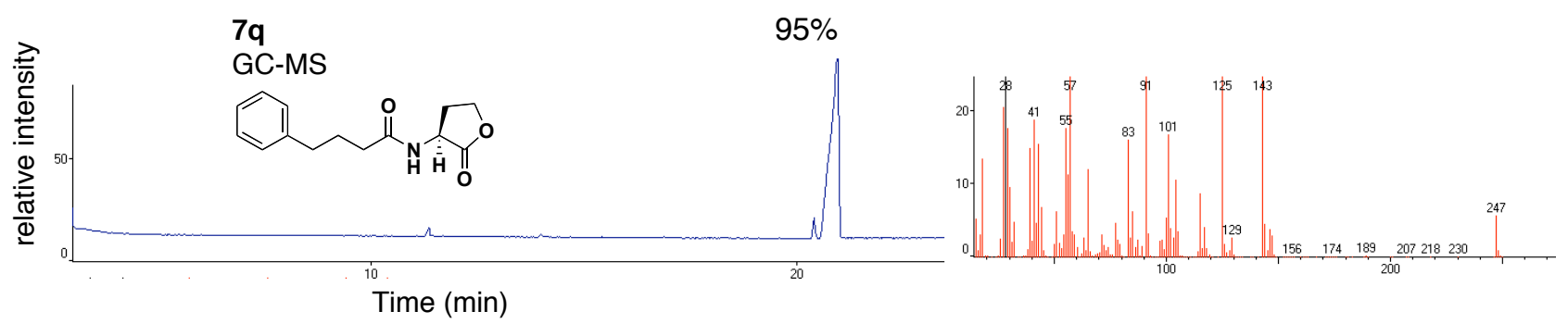

$\boldsymbol{N}$-(4-phenylbutanoyl)-D-homoserine lactone (7r): ${ }^{1} \mathrm{H} \mathrm{NMR}\left(300 \mathrm{MHz}, \mathrm{CDCl}_{3}\right) \delta=7.31(\mathrm{~m}$, 2H, Ar-H), 7.21 (m, 3H, Ar-H), 6.10 (d, 1H, J=4.7 Hz, NH), 4.59 (ddd, 1H, J=5.9 Hz, CH-lac), 4.47 (td, 1H, J=1.2 Hz, CH-lac), 4.31 (ddd, 1H, J=5.8 Hz, CH-lac), 2.86 (ddd, 1H, J=1.2 Hz, CHlac), 2.69 (t, 2H, J=7.2 Hz, $\mathrm{CH}_{2}$ ), 2.36 (t, 2H, J=7.8 Hz, $\mathrm{CH}_{2}$ ), 2.18 (ddd, 1H, J=3.2 Hz, CH-lac), 2.04 (p, 2H, J=7.1 Hz, $\left.\mathrm{CH}_{2}\right) ;{ }^{13} \mathrm{C} \mathrm{NMR}\left(75 \mathrm{MHz} \mathrm{CDCl}_{3}\right) \delta=175.6,173.5,167.6,163.9,141.5$, 128.7, 128.6, 126.2, 115.1, 115.0, 66.3, 59.4, 49.4, 35.5, 35.3, 30.7, 27.0; GC-MS: expected $\mathrm{m} / \mathrm{z}=247$, observed $[\mathrm{M}+]=247 ;\left[\alpha_{\mathrm{D}}\right]=-24.1\left(\mathrm{c}=4.0 \mathrm{mg} / \mathrm{mL} ; \mathrm{CHCl}_{3}\right) ; \mathrm{IR}\left(\mathrm{cm}^{-1}\right): 3309,2966,2685$, 23559, 2338, 1772, 1669, 1539, 1556, 1221, 1201. 


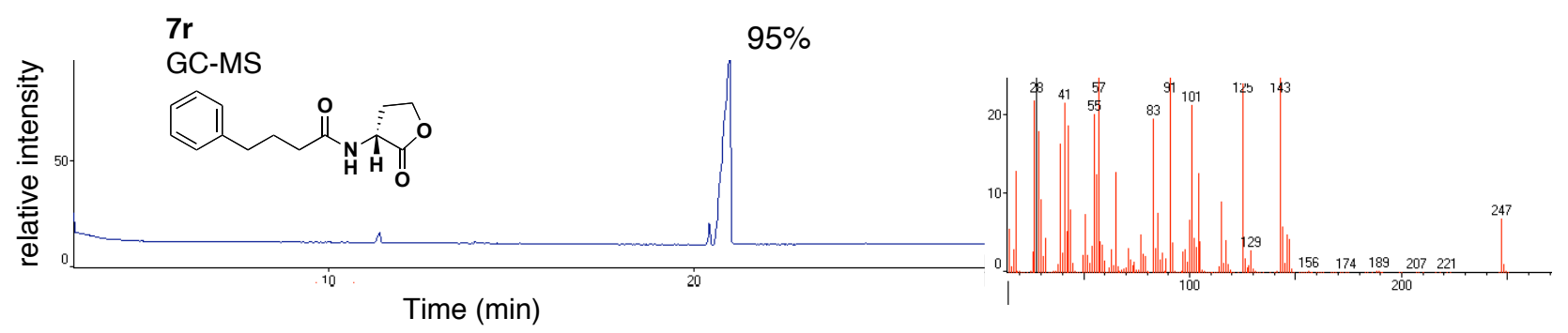

$\boldsymbol{N}$-(3-oxo-hexanoyl)-L-homoserine lactone (8a): ${ }^{1} \mathrm{H}$ NMR $\left(300 \mathrm{MHz}, \mathrm{CDCl}_{3}\right) \delta=7.85$ (s, 1H, NH), 4.67 (ddd, 1H, J=6.7 Hz, CH-lac), 4.57 (td, 1H, J=1.3 Hz, CH-lac), 4.34 (ddd, 1H, $\mathrm{J}=6.1 \mathrm{~Hz}, \mathrm{CH}-\mathrm{lac}$ ), 3.52 (s, 2H, $\mathrm{CH}_{2}$ ), 2.82 (dddd, 1H, J=1.2 Hz, CH-lac), 2.56 (t, 2H, J=7.2 Hz, $\mathrm{CH}_{2}$ ) 2.33 (ddd, 1H, J=2.4 Hz, CH-lac), 1.64 (p, 2H, J=7.2 Hz, $\mathrm{CH}_{2}$ ), 0.98 (t, 3H, J=6.5 Hz, $\mathrm{CH}_{3}$ ); ${ }^{13} \mathrm{C}$ NMR $\left(75 \mathrm{MHz}, \mathrm{CDCl}_{3}\right.$ ) $\delta=204.7,173.1,164.9,64.2,47.4$, 46.3, 44.0, 28.1, 15.1, 11.8; MS(ESI): expected $\mathrm{m} / \mathrm{z}=213$, observed $[\mathrm{M}+\mathrm{Na}]=236 ;\left[\alpha_{\mathrm{D}}\right]=+12.2\left(\mathrm{c}=2.7 \mathrm{mg} / \mathrm{mL} ; \mathrm{CHCl}_{3}\right) ; \mathrm{IR}$ $\left(\mathrm{cm}^{-1}\right): 3286,3966,1783,1718,1646,1545,1171$.

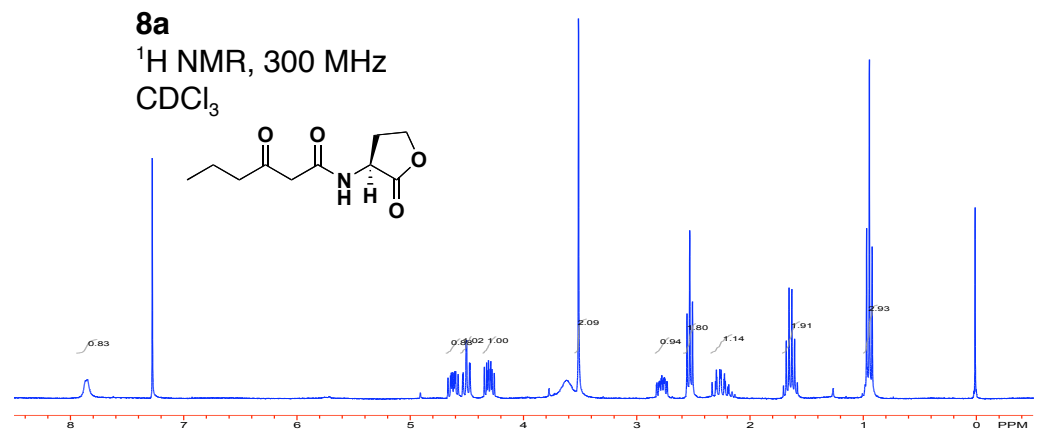

$\boldsymbol{N}$-(3-oxo-octanoyl)-L-homoserine lactone (8b): ${ }^{1} \mathrm{H} \mathrm{NMR}\left(300 \mathrm{MHz}, \mathrm{CDCl}_{3}\right) \delta=7.95(\mathrm{~s}, 1 \mathrm{H}$, $\mathrm{NH}$, 4.67 (ddd, 1H, J=6.7 Hz, CH-lac), 4.53 (td, 1H, J=1.3 Hz, CH-lac), 4.34 (ddd, 1H, J=6.1 $\mathrm{Hz}, \mathrm{CH}-\mathrm{lac}$ ), 3.52 (s, 2H, $\mathrm{CH}_{2}$ ), 2.81 (dddd, 1H, J=1.2 Hz, CH-lac), 2.57 (t, 2H, J=7.2 Hz, $\mathrm{CH}_{2}$ ) 2.34 (ddd, 1H, J=2.4 Hz, CH-lac), 1.64 (p, 2H, J=7.2 Hz, $\left.\mathrm{CH}_{2}\right), 1.43$ (m, 4H, J=6.4 Hz, $\left.\left(\mathrm{CH}_{2}\right)_{4}\right)$, $0.91\left(\mathrm{t}, 3 \mathrm{H}, \mathrm{J}=6.5 \mathrm{~Hz}, \mathrm{CH}_{3}\right) ;{ }^{13} \mathrm{C} \mathrm{NMR}\left(75 \mathrm{MHz} \mathrm{CDCl}_{3}\right) \delta=206.7,175.0,166.7,66.3,66.1,49.3$, 48.4, 44.0, 31.3, 30.0, 23.2, 22.6, 14.1; MS(ESI): expected $\mathrm{m} / \mathrm{z}=241$, observed [M+Na]=264; $\left[\alpha_{\mathrm{D}}\right]=+16.9\left(\mathrm{c}=2.7 \mathrm{mg} / \mathrm{mL} ; \mathrm{CHCl}_{3}\right) ; \mathrm{IR}\left(\mathrm{cm}^{-1}\right): 3684,3020,2401,1783,1712,1674,1527,1216$.

$8 b$

${ }^{1} \mathrm{H} \mathrm{NMR}, 300 \mathrm{MHz}$ $\mathrm{CDCl}_{3}$
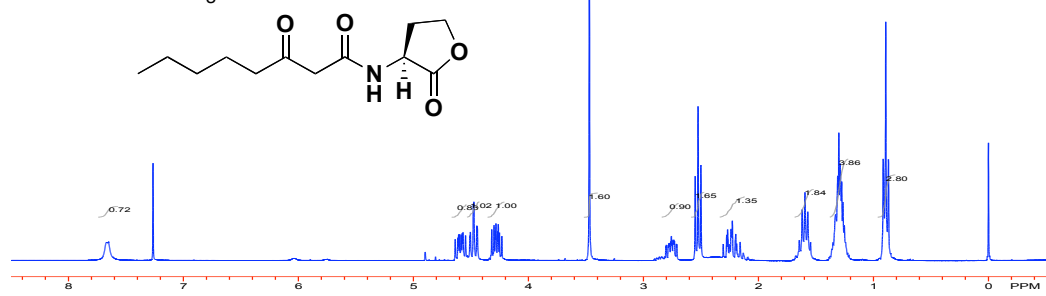
$N$-(3-oxo-decanoyl)-L-homoserine lactone (8c): ${ }^{1} \mathrm{H}$ NMR $\left(300 \mathrm{MHz}, \mathrm{CDCl}_{3}\right) 7.68(\mathrm{~d}, 1 \mathrm{H}$, $\mathrm{J}=4.9 \mathrm{~Hz}, \mathrm{NH}$ ), 4.65 (ddd, 1H, J=9.2 Hz, CH-lac), 4.53 (t, 1H, J=8.9 Hz, CH-lac), 4.32 (ddd, 1H, $\mathrm{J}=6.2 \mathrm{~Hz}, \mathrm{CH}-\mathrm{lac}$ ), 3.47 (s, 2H, $\mathrm{CH}_{2}$ ), 2.79 (dddd, 1H, J=1.3 Hz, CH-lac), 2.55 (t, 2H, J=7.3 Hz, $\mathrm{CH}_{2}$ ), 2.32 (ddd, 1H, J=2.4 Hz, CH-lac), $1.61\left(\mathrm{~m}, 2 \mathrm{H}, \mathrm{CH}_{2}\right), 1.28\left(\mathrm{~m}, 8 \mathrm{H},\left(\mathrm{CH}_{2}\right)_{4}\right), 0.89$ (t, 3H, $\left.\mathrm{J}=5.4 \mathrm{~Hz}, \mathrm{CH}_{3}\right) ;{ }^{13} \mathrm{C} \mathrm{NMR}\left(75 \mathrm{MHz}, \mathrm{CDCl}_{3}\right) \delta=206.7,175.1,166.6,66.3,66.1,49.2,48.4$, 44.1, 31.8, 29.9, 29.2, 29.1, 23.6, 22.8, 14.2; MS(ESI): expected $\mathrm{m} / \mathrm{z}=269$, observed $[\mathrm{M}+\mathrm{Na}]=292$; $\left[\alpha_{\mathrm{D}}\right]=+16.7\left(\mathrm{c}=3.4 \mathrm{mg} / \mathrm{mL} ; \mathrm{CHCl}_{3}\right) ; \mathrm{IR}\left(\mathrm{cm}^{-1}\right): 3295,2923,2851,1775,1716,1645,1547,1176$.

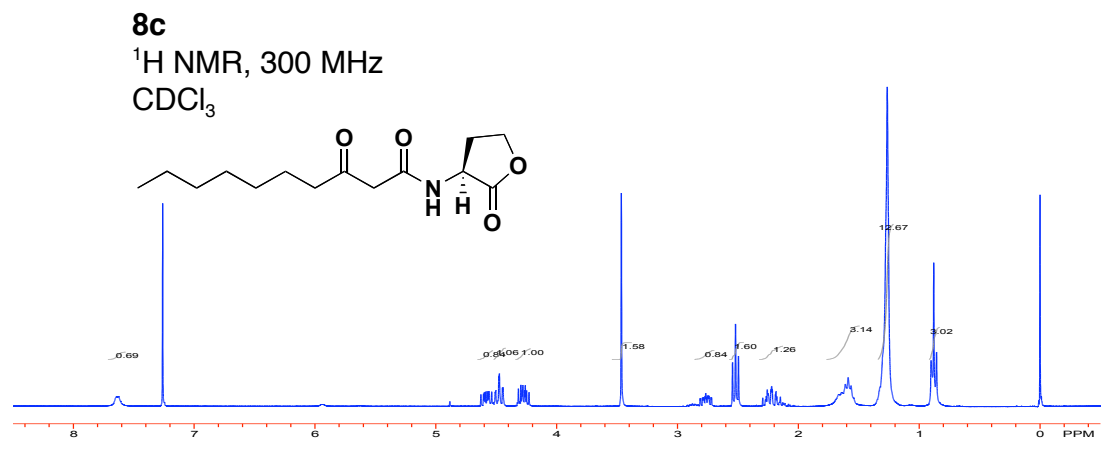

$\boldsymbol{N}$-(3-oxo-dodecanoyl)-L-homoserine lactone (8d): ${ }^{1} \mathrm{H} \mathrm{NMR}\left(300 \mathrm{MHz}, \mathrm{CDCl}_{3}\right) 7.68$ (d, 1H, J=6.0 Hz, NH), 4.65 (ddd, 1H, J=5.9 Hz, CH-lac), 4.50 (td, 1H, J=1.1 Hz, CH-lac), 4.32 (ddd, 1H, J=6.1 Hz, CH-lac), 3.47 (s, 2H, $\mathrm{CH}_{2}$ ), 2.79 (ddd, 1H, J=7.0 Hz, CH-lac), 2.55 (t, 2H, $\left.\mathrm{J}=7.3 \mathrm{~Hz}, \mathrm{CH}_{2}\right), 2.29$ (ddd, 1H, J=2.2 Hz, CH-lac), $1.60\left(\mathrm{~m}, 2 \mathrm{H}, \mathrm{CH}_{2}\right), 1.26\left(\mathrm{~m}, 12 \mathrm{H},\left(\mathrm{CH}_{2}\right)_{6}\right)$, 0.89 (t, 3H, J=6.1 Hz, $\left.\mathrm{CH}_{3}\right) ;{ }^{13} \mathrm{C} \mathrm{NMR}\left(75 \mathrm{MHz} \mathrm{CDCl}_{3}\right) \delta=206.7,175.1,174.1,166.7,66.3$, 66.1, 49.4, 49.2, 48.9, 48.4, 44.1, 36.4, 32.0, 30.7, 29.9, 29.6, 29.5, 29.5, 29.4, 29.2, 25.7; MS(ESI): expected $\mathrm{m} / \mathrm{z}=297$, observed $[\mathrm{M}+\mathrm{Na}]=320 ;\left[\alpha_{\mathrm{D}}\right]=+11.8\left(\mathrm{c}=3.6 \mathrm{mg} / \mathrm{mL} ; \mathrm{CHCl}_{3}\right) ; \mathrm{IR}$ $\left(\mathrm{cm}^{-1}\right): 3295,2922,2851,1775,1716,1644,1547,1171,1016$.

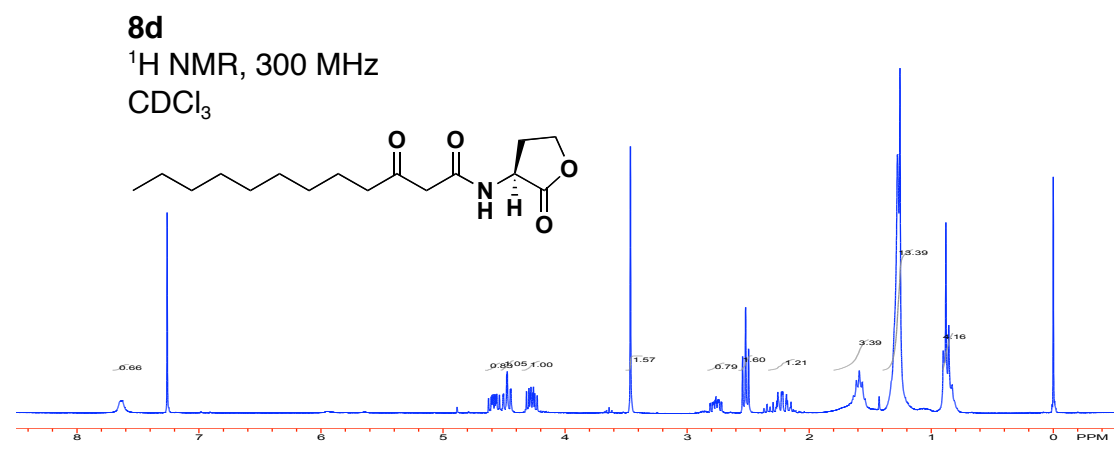

$\boldsymbol{N}$-(3-oxo-tetradecanoyl)-L-homoserine lactone (8e): ${ }^{1} \mathrm{H} \mathrm{NMR}\left(300 \mathrm{MHz}, \mathrm{CDCl}_{3}\right) 7.68$ (d, $1 \mathrm{H}, \mathrm{J}=6.0 \mathrm{~Hz}, \mathrm{NH}), 4.66$ (ddd, 1H, J=5.9 Hz, CH-lac), 4.56 (td, 1H, J=1.1 Hz, CH-lac), 4.34 (ddd, 1H, J=6.1 Hz, CH-lac), 3.50 (s, 2H, $\mathrm{CH}_{2}$ ), 2.86 (ddd, 1H, J=7.0 Hz, CH-lac), 2.30 (t, 2H, $\left.\mathrm{J}=7.3 \mathrm{~Hz}, \mathrm{CH}_{2}\right), 2.28$ (ddd, $\left.1 \mathrm{H}, \mathrm{J}=2.2 \mathrm{~Hz}, \mathrm{CH}-\mathrm{lac}\right), 1.60\left(\mathrm{~m}, 2 \mathrm{H}, \mathrm{CH}_{2}\right), 1.26\left(\mathrm{~m}, 12 \mathrm{H},\left(\mathrm{CH}_{2}\right)_{6}\right)$, 
$0.89\left(\mathrm{t}, 3 \mathrm{H}, \mathrm{J}=6.1 \mathrm{~Hz}, \mathrm{CH}_{3}\right) ;{ }^{13} \mathrm{C}$ NMR $\left(75 \mathrm{MHz}, \mathrm{CDCl}_{3}\right) \delta=175.0,166.7,66.3,66.0,49.5,36.1$, 32.1, 30.7, 29.8, 29.6, 29.5, 29.5, 29.4, 29.2, 25.7; MS(ESI): expected $\mathrm{m} / \mathrm{z}=325$, observed $[\mathrm{M}+\mathrm{Na}]=348 ;\left[\alpha_{\mathrm{D}}\right]=+14.0\left(\mathrm{c}=2.5 \mathrm{mg} / \mathrm{mL} ; \mathrm{CHCl}_{3}\right) ; \mathrm{IR}\left(\mathrm{cm}^{-1}\right): 3921,3315,2852,1777,1716$, $1645,1548,1174,1014$.

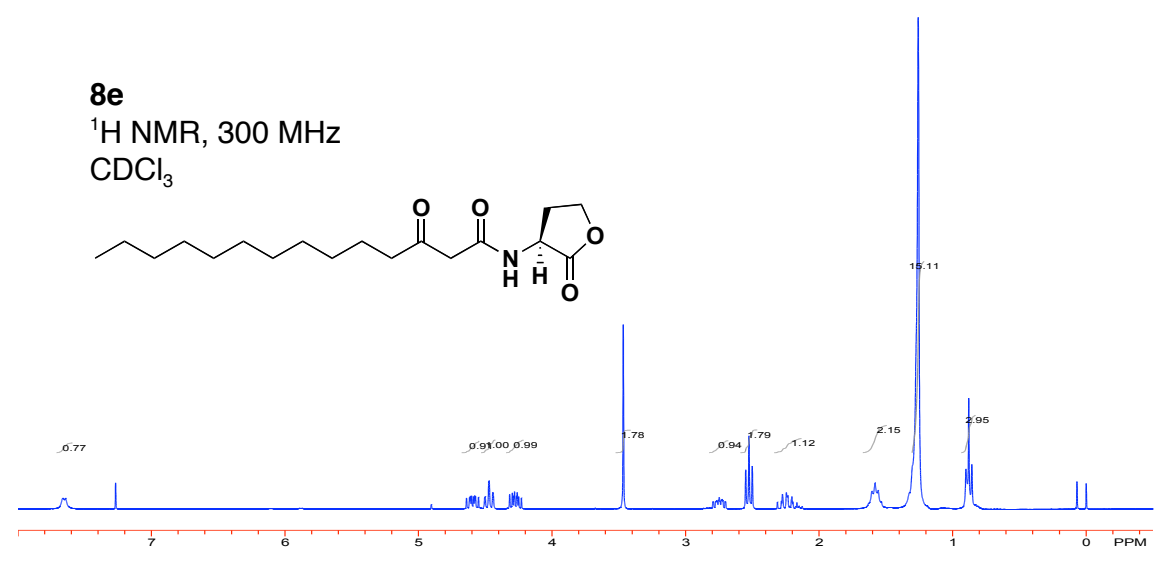

$\boldsymbol{N}$-(3-oxo-3-phenylpropanoyl)-L-homoserine lactone (8f): ${ }^{1} \mathrm{H}$ NMR (300 $\left.\mathrm{MHz}, \mathrm{CDCl}_{3}\right)$ $\delta=7.66(\mathrm{~s}, 1 \mathrm{H}, \mathrm{NH}), 7.64$ (m, 3H, CH-Ar), 7.20 (d, 2H, CH-Ar), 4.60 (ddd, 1H, J=2.0 Hz, CHlac), 4.47 (td, 1H, J=1.4 Hz, CH-lac), 4.28 (ddd, 1H, J=3.2 Hz, CH-lac), 3.80 (s, 2H, $\mathrm{CH}_{2}$ ), 3.53 (s, 2H, $\mathrm{CH}_{2}$ ), 2.70 (ddd, 1H, J=1.1 Hz, CH-lac), 2.23 (ddd, 1H, J=8.9 Hz, CH-lac); ${ }^{13} \mathrm{C}$ NMR $(75$ $\left.\mathrm{MHz} \mathrm{CDCl}_{3}\right) \delta=204.0,175.1,167.0,132.9,129.8,129.6,129.2,127.8,66.2,50.8,49.3,47.6$, 29.7; MS(ESI): expected m/z=261, observed $[\mathrm{M}+\mathrm{Na}]=284 ;\left[\alpha_{\mathrm{D}}\right]=+14.6$ (c=3.4 $\left.\mathrm{mg} / \mathrm{mL} ; \mathrm{CHCl}_{3}\right)$; IR $\left(\mathrm{cm}^{-1}\right): 3335,3054,2916,1176,1772,1663,1538,1179,1022$.

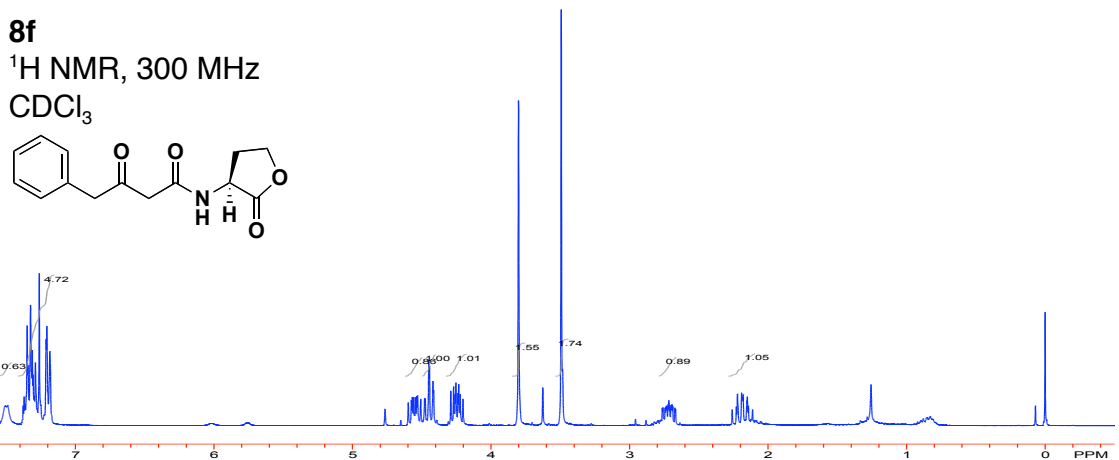

$\mathbf{N}$-(3-oxo-3-phenylpropanoyl)-D-homoserine lactone (8g): ${ }^{1} \mathrm{H}$ NMR $\left(300 \mathrm{MHz}, \mathrm{CDCl}_{3}\right)$ $\delta=7.70(\mathrm{~s}, 1 \mathrm{H}, \mathrm{NH}), 7.69(\mathrm{~m}, 3 \mathrm{H}, \mathrm{CH}-\mathrm{Ar}), 7.21$ (d, 2H, CH-Ar), 4.59 (ddd, 1H, J=2.0 Hz, CHlac), 4.49 (td, 1H, J=1.2 Hz, CH-lac), 4.30 (ddd, 1H, J=2.1 Hz, CH-lac), 3.80 (s, 2H, $\mathrm{CH}_{2}$ ), 3.53 (s, 2H, $\mathrm{CH}_{2}$ ), 2.74 (ddd, 1H, J=1.0 Hz, CH-lac), 2.23 (ddd, 1H, J=9.0 Hz, CH-lac); ${ }^{13} \mathrm{C}$ NMR $(75$ 
$\left.\mathrm{MHz}, \mathrm{CDCl}_{3}\right) \delta=204.1,174.9,167.1,132.7,129.7,129.6,129.2,128.8,127.8,66.2,50.9,49.4$, 47.3, 29.8; $\mathrm{MS}(\mathrm{ESI})$ : expected $\mathrm{m} / \mathrm{z}=261$, observed $[\mathrm{M}+\mathrm{Na}]=284 ;\left[\alpha_{\mathrm{D}}\right]=-6.2(\mathrm{c}=1.5 \mathrm{mg} / \mathrm{mL}$; $\left.\mathrm{CHCl}_{3}\right)$; IR $\left(\mathrm{cm}^{-1}\right): 3335,3054,2916,1176,1772,1663,1538,1179,1022$.

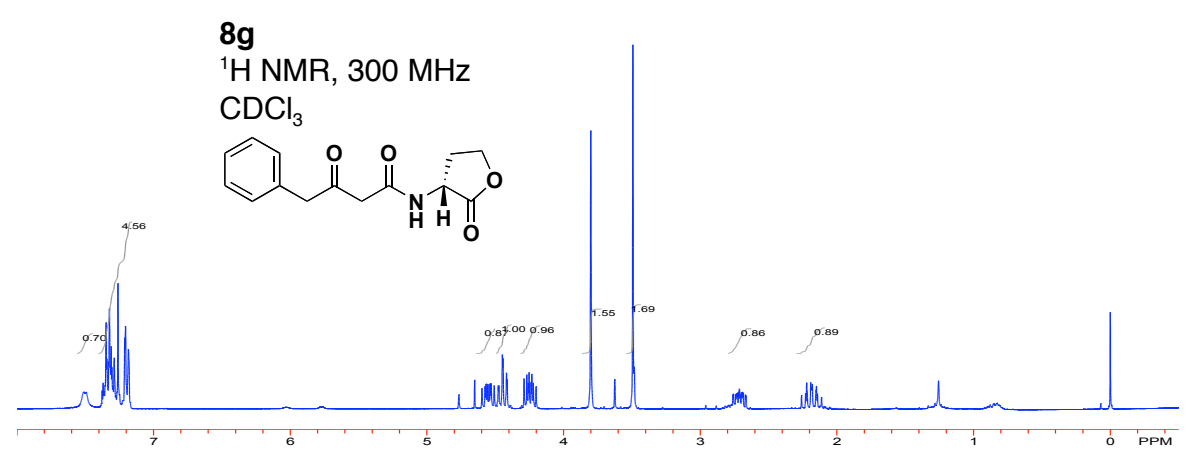

$\boldsymbol{N}$-(3-oxo-octanoyl)-D-homoserine lactone (8h): ${ }^{1} \mathrm{H}$ NMR $\left(300 \mathrm{MHz}, \mathrm{CDCl}_{3}\right) \delta=7.95$ (s, 1H, NH), 4.67 (ddd, 1H, J=6.7 Hz, CH-lac), 4.53 (td, 1H, J=1.3 Hz, CH-lac), 4.34 (ddd, 1H, $\mathrm{J}=6.1 \mathrm{~Hz}, \mathrm{CH}-\mathrm{lac}$ ), 3.52 (s, 2H, $\mathrm{CH}_{2}$ ), 2.81 (dddd, 1H, J=1.2 Hz, CH-lac), 2.57 (t, 2H, J=7.2 Hz, $\mathrm{CH}_{2}$ ) 2.34 (ddd, 1H, J=2.4 Hz, CH-lac), 1.64 (p, 2H, J=7.2 Hz, CH$)_{2}, 1.43$ (m, 4H, J=6.4 Hz, $\left.\left(\mathrm{CH}_{2}\right)_{4}\right), 0.91\left(\mathrm{t}, 3 \mathrm{H}, \mathrm{J}=6.5 \mathrm{~Hz}, \mathrm{CH}_{3}\right) ;{ }^{13} \mathrm{C} \mathrm{NMR}\left(75 \mathrm{MHz}, \mathrm{CDCl}_{3}\right) \delta=206.7,175.0,166.7,66.3$, 66.1, 49.3, 48.4, 44.0, 31.3, 30.0, 23.2, 22.6, 14.1; MS(ESI): expected $\mathrm{m} / \mathrm{z}=241$, observed $[\mathrm{M}+\mathrm{Na}]=264 ;\left[\alpha_{\mathrm{D}}\right]=-19.6\left(\mathrm{c}=2.7 \mathrm{mg} / \mathrm{mL} ; \mathrm{CHCl}_{3}\right) ; \mathrm{IR}\left(\mathrm{cm}^{-1}\right): 3684,3020,2401,1783,1712$, $1674,1527,1216$.

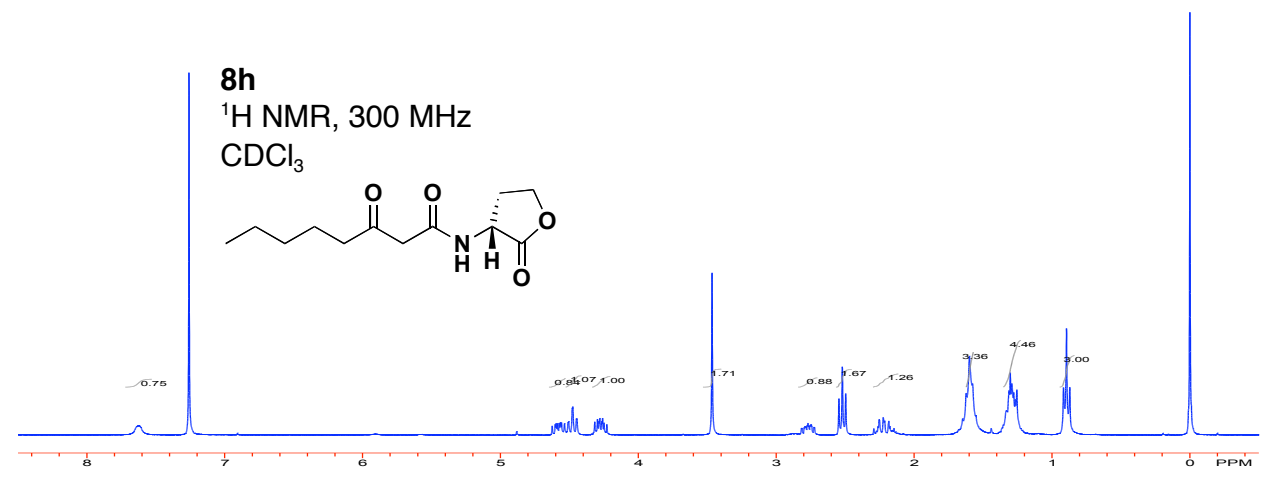


Evaluation of AHL Mosher amides. The enantiopurity of the AHLs synthesized via Scheme 1 was assessed through the characterization of AHL Mosher amide derivatives (Figure $\mathrm{S}-2)$. This solid-phase route was used to synthesize $R$-Mosher amide diastereomers starting from both the L-and D-methionine loaded resins (3). Analysis of the ${ }^{1} \mathrm{H} \mathrm{NMR}\left(300 \mathrm{MHz}, \mathrm{CDCl}_{3}\right)$ spectra of the diastereomers indicated that the AHL de was $>95 \%$ (as calculated from 100(a-a') or $100\left(b^{-} b^{\prime}\right)$ where $a, a^{\prime}, b, b^{\prime}$ are the fractional yields based on the integration of respective peaks in the NMR spectra). ${ }^{5}$

(R)-(+)- $\alpha$-Methoxy- $\alpha$-triflouromethylphenylacetanoyl-D-homoserine lactone

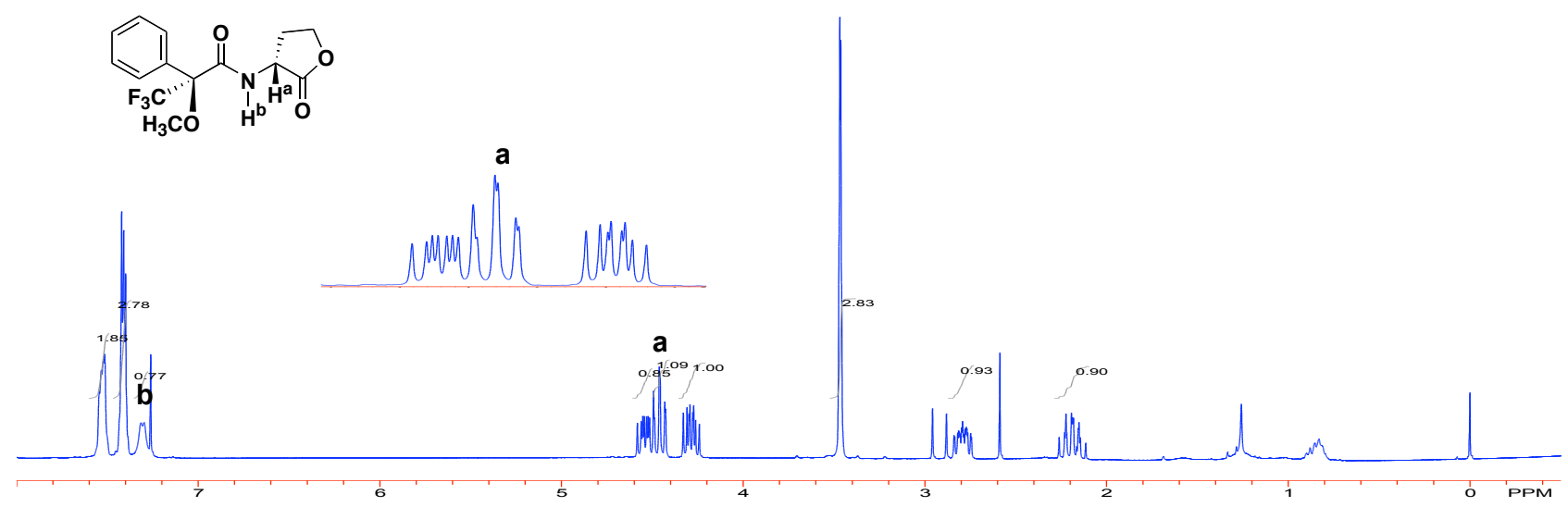

$(R)-(+)-\alpha-M e t h o x y-\alpha$-triflouromethylphenylacetanoyl-L-homoserine lactone
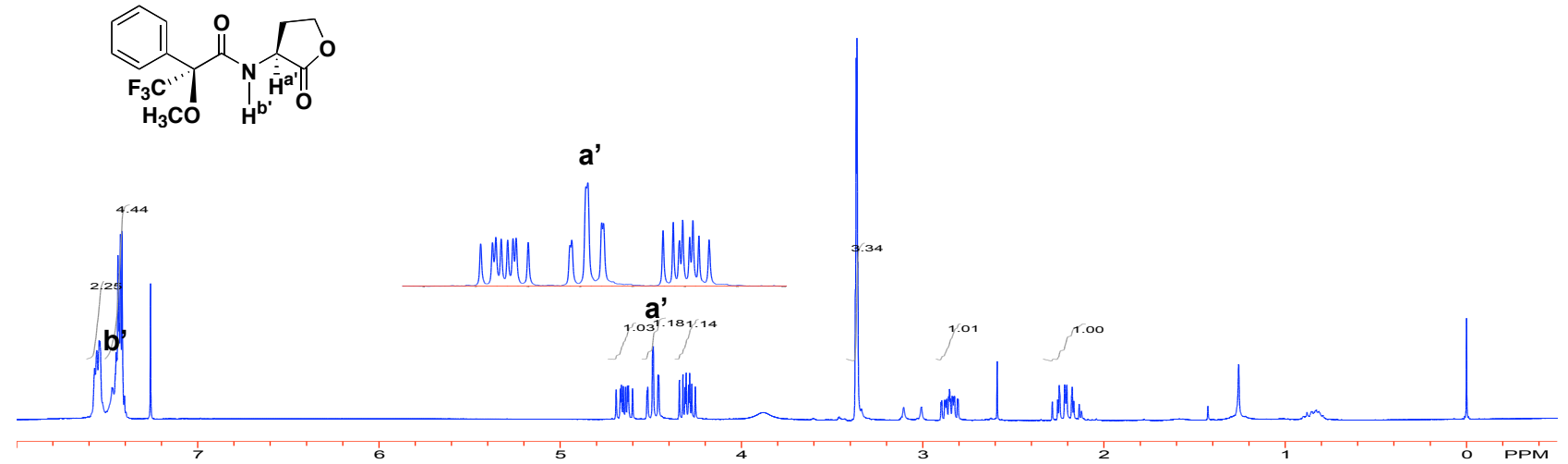

Figure S-2. ${ }^{1} \mathrm{H}$ NMR spectra for $R$-Mosher amide $\mathrm{AHL}$ derivatives (300 MHz, $\mathrm{CDCl}_{3}$ ). 


\section{Biological screening protocols and supplementary assay data}

Compound handling and reagents. Stock solution of synthetic compounds $(10 \mathrm{mM}$ and 100 $\mathrm{mM}$ ) were prepared in either ethyl acetate or $\mathrm{CHCl}_{3}$ and stored at $-20{ }^{\circ} \mathrm{C}$ in sealed vials. The solutions were allowed to come to room temperature prior to use in assays. Solvent resistant polypropylene (Corning Costar cat. no. 3790) or polystyrene (Corning Costar cat. no. 3997) 96well plates were used when appropriate. All biological reagents were purchased from Fisher and used according to enclosed instructions. AB Minimal media was prepared containing $1.0 \mathrm{~g} / \mathrm{L}$ $\mathrm{NH}_{4} \mathrm{Cl}, 0.3 \mathrm{~g} / \mathrm{L} \mathrm{MgSO}_{4} \cdot 7 \mathrm{H}_{2} \mathrm{O}, 0.15 \mathrm{~g} / \mathrm{L} \mathrm{KCl}, 0.01 \mathrm{~g} / \mathrm{L} \mathrm{CaCl}_{2}, 2.5 \mathrm{mg} / \mathrm{L} \mathrm{FeSO} \cdot \cdot 7 \mathrm{H}_{2} \mathrm{O}, 5.0 \mathrm{~g} / \mathrm{L}$ glucose, $1.0 \mathrm{~g} / \mathrm{L} \mathrm{NaH}_{2} \mathrm{PO}_{4}$, and $3.0 \mathrm{~g} / \mathrm{L} \mathrm{K}_{2} \mathrm{HPO}_{4}, \mathrm{pH}=6.8$. M9 media used in biofilm assays was prepared as described. ${ }^{6}$ Buffers and solutions for Miller absorbance assays were prepared as described. $^{7}$

Control compounds. Compounds $\mathbf{7} \mathrm{g}^{8}$ and $\mathbf{8} \mathbf{h}^{9}$ were prepared according to the solid-phase methods described above. Compound $\mathbf{9}$ was synthesized using a modified solution-phase procedure ${ }^{10}$ that proceeded as follows: $\beta$-keto acid $\mathbf{5 d}(483 \mathrm{mg}, 1.87 \mathrm{mmol})$ and 2-aminophenol (204 mg, $1.87 \mathrm{mmol}$ ) were dissolved in $10 \mathrm{~mL} \mathrm{DMF}$, after which 1-(3-dimethylaminopropyl)-3ethylcarbodiimide hydrochloride (EDC, $456 \mathrm{mg}, 2.38 \mathrm{mmol}$ ), 4-dimethylaminopyridine (DMAP, $228 \mathrm{mg}, 1.87 \mathrm{mmol}$ ), and $N, N$-diisopropylethylamine (DIPEA, $500 \mu \mathrm{L}, 2.87 \mathrm{mmol}$ ) were added. The reaction mixture was stirred at room temperature until TLC indicated completion $(12 \mathrm{~h})$. The reaction mixture was diluted with $30 \mathrm{~mL}$ of diethyl ether and washed $2 \mathrm{x}$ with $30 \mathrm{~mL} 10 \%$ citric acid, $2 \times 30 \mathrm{~mL}$ saturated $\mathrm{NaHCO}_{3}$, and $1 \times 15 \mathrm{~mL}$ saturated $\mathrm{NaCl}$. The ether layer was separated, dried with magnesium sulfate, and the solvent removed in vacuo. The resulting solid was immediately subjected to $95 \% \mathrm{TFA} / \mathrm{H}_{2} \mathrm{O}(30 \mathrm{~min})$ to affect ketal deprotection. Extraction of the reaction mixture $(3 \times 15 \mathrm{~mL})$ with $\mathrm{CHCl}_{3}$, drying over $\mathrm{MgSO}_{4}$, and removal of $\mathrm{CHCl}_{3}$ in vacuo gave a yellow-brown solid. Purification by flash silica gel chromatography (1:1 EtOAc/hexane) yielded $\mathbf{9}$ as a white solid. $228 \mathrm{mg}, 40 \%$ overall yield. Compounds $\mathbf{7 g}, \mathbf{8 h}$, and $\mathbf{9}$ were stored at $20^{\circ} \mathrm{C}$ until required for use.

Instrumentation. Absorbance and fluorescence assay results were obtained using a PerkinElmer Wallac 2100 EnVision $^{\mathrm{TM}}$ multilabel plate reader using Wallac Manager v1.03 software. A filter of $600 \mathrm{~nm}$ was used for reading bacterial cell density. Filters of $420 \mathrm{~nm}$ and $550 \mathrm{~nm}$ were used for Miller-type absorbance assays. ${ }^{11}$ Filters of $485 \mathrm{~nm}$ for excitation and 535 $\mathrm{nm}$ for emission were used for evaluating the production of green fluorescent protein (GFP) in fluorescence assays. Biofilms were visualized with a Bio-Rad MRC-1024 laser scanning confocal microscope using Lasersharp v3.2 software. Biofilm visualization data was manipulated using Confocal Assistant v4.02 software. ${ }^{12}$

Agrobacterium tumefaciens reporter gene assays. An appropriate amount of concentrated AHL stock solution, to give a final concentration of $100 \mathrm{nM}$, was added to an empty culture tube, and the solvent was allowed to evaporate. An overnight culture of A. tumefaciens WCF47(pCF372) ${ }^{8}$ was diluted to an $\mathrm{OD}_{600}$ (optical density) of 0.1 in fresh $\mathrm{AB}$ minimal medium containing $400 \mu \mathrm{g} / \mathrm{mL}$ octopine and $50 \mu \mathrm{g} / \mathrm{mL}$ streptomycin. A $1 \mathrm{~mL}$ portion of the diluted culture was added to the tubes containing AHLs. Tubes were grown at $28{ }^{\circ} \mathrm{C}$ for $12-16 \mathrm{~h}$ in a rotary shaking incubator $(200 \mathrm{rpm})$. The cultures were then assayed for $\beta$-galactosidase activity 
following the Miller assay method. ${ }^{11}$ Briefly, $100 \mu \mathrm{L}$ aliquots of bacteria from each of the tubes were added to wells of a polystyrene 96-well plate and the $\mathrm{OD}_{600}$ of each well was recorded. Next, $50 \mathrm{~mL}$ aliquots from each well were transferred to a solvent resistant 96-well plate containing $200 \mu \mathrm{L} \mathrm{Z}$ buffer, $8 \mu \mathrm{L} \mathrm{CHCl}_{3}$ and $4 \mu \mathrm{L} 0.1 \%$ aq. sodium dodecylsulfate (SDS). This suspension was mixed via repetitive pipetting, after which the $\mathrm{CHCl}_{3}$ was allowed to settle. A $100-\mu \mathrm{L}$ aliquot from each well was transferred to a fresh polystyrene 96-well plate, and $20 \mu \mathrm{L}$ of substrate, $o$-nitrophenyl- $\beta$-D-galactopyranoside (ONPG, $4 \mu \mathrm{g} / \mathrm{mL}$ in phosphate buffer), was added at time zero. After the development of appropriate yellow color ( $c$ a $15-35 \mathrm{~min})$, the reaction was terminated by the addition of $50 \mu \mathrm{L}$ of $1 \mathrm{M} \mathrm{Na}_{2} \mathrm{CO}_{3}$. Absorbance at $420 \mathrm{~nm}$ and 550 $\mathrm{nm}$ was measured for each well using a plate reader, and Miller units were calculated according to standard mathods. ${ }^{11}$ Similar methods were used for antagonism assays, except the concentration of AHL analog used was $10^{4} \mathrm{nM}$, and OOHL (8b) stock solution was added to each tube such that its concentration was $100 \mathrm{nM}$ (Figure S-3). Compounds that showed good inhibitory activity at $10^{4} \mathrm{nM}$ were then tested through a range of concentrations against OHHL $(\mathbf{8 b})$ at $100 \mathrm{nM}$, from $10^{4} \mathrm{nM}$ to $1 \mathrm{nM}$ (shown in Figure S-5). All assays were performed in triplicate.

Pseudomonas aeruginosa reporter gene assays. An appropriate amount of concentrated stock solution, to give a final concentration of $1 \mu \mathrm{M}$, was added to a polypropylene 96-well plate, and the solvent was allowed to evaporate. An overnight culture of P. aeruginosa PAOJP2(plasI-LVAgfp) ${ }^{6}$ was diluted to an $\mathrm{OD}_{600}$ of 0.1 in fresh $\mathrm{LB}$ medium containing $200 \mu \mathrm{g} / \mathrm{mL}$ carbenicillin. $200 \mu \mathrm{L}$ of the diluted culture was added to each well of the plate and incubated at $37^{\circ} \mathrm{C}$ for $6 \mathrm{~h}$ in a rotary shaking incubator $(200 \mathrm{rpm})$. Cultures were transferred to a polystyrene 96-well plate, GFP expression was measured using a plate reader, and this value was normalized to cell density. Similar methods were used for antagonism assays, except the concentration of AHL analog used was $400 \mu \mathrm{M}$, and ODHL (8d) stock solution was added to each well such that its concentration was $1 \mu \mathrm{M}$ (Figure S-4). Compounds that showed good inhibitory activity at 400 $\mu \mathrm{M}$ were then tested through a range of concentrations against ODHL (8d) at $1 \mu \mathrm{M}$, from 400 $\mu \mathrm{M}$ to $4 \mathrm{nM}$ (shown in Figure S-6). All assays were performed in triplicate. 


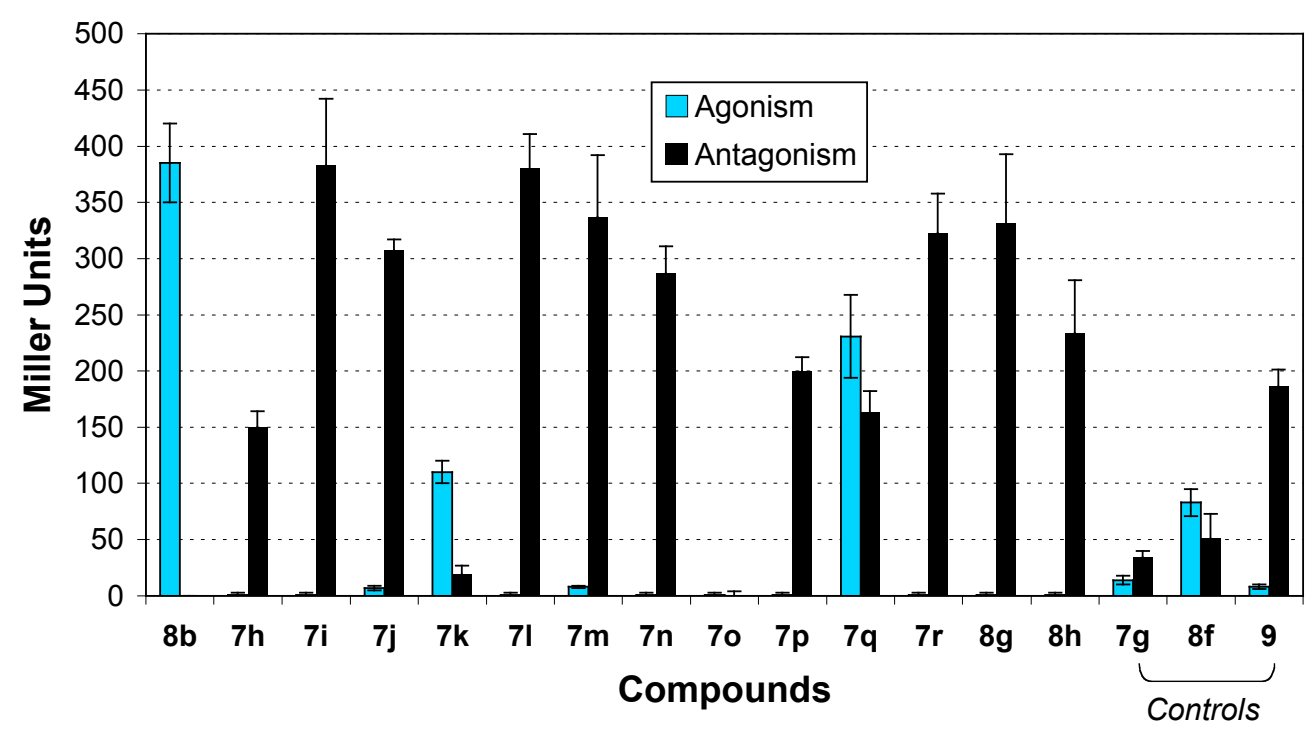

Figure S-3. A. tumefaciens reporter gene screening data for AHL derivatives $\mathbf{7 h}-\mathbf{7 r}$ and $\mathbf{8 f}-\mathbf{8 h}$. Data for control compounds $\mathbf{7 g}, \mathbf{8 f}$, and 9 are shown. Reporter strain: WCF47(pCF372). ${ }^{8}$ Miller units report relative $\beta$-galactosidase activity with ONPG as colometric substrate. Compound concentration in agonism assays: $100 \mathrm{nM}$. Compound concentration in antagonism assays: $10^{4} \mathrm{nM}$ against $100 \mathrm{nM}$ native ligand $\mathbf{8 b}$ (OOHL). Error bars calculated from at least three replicate screens.

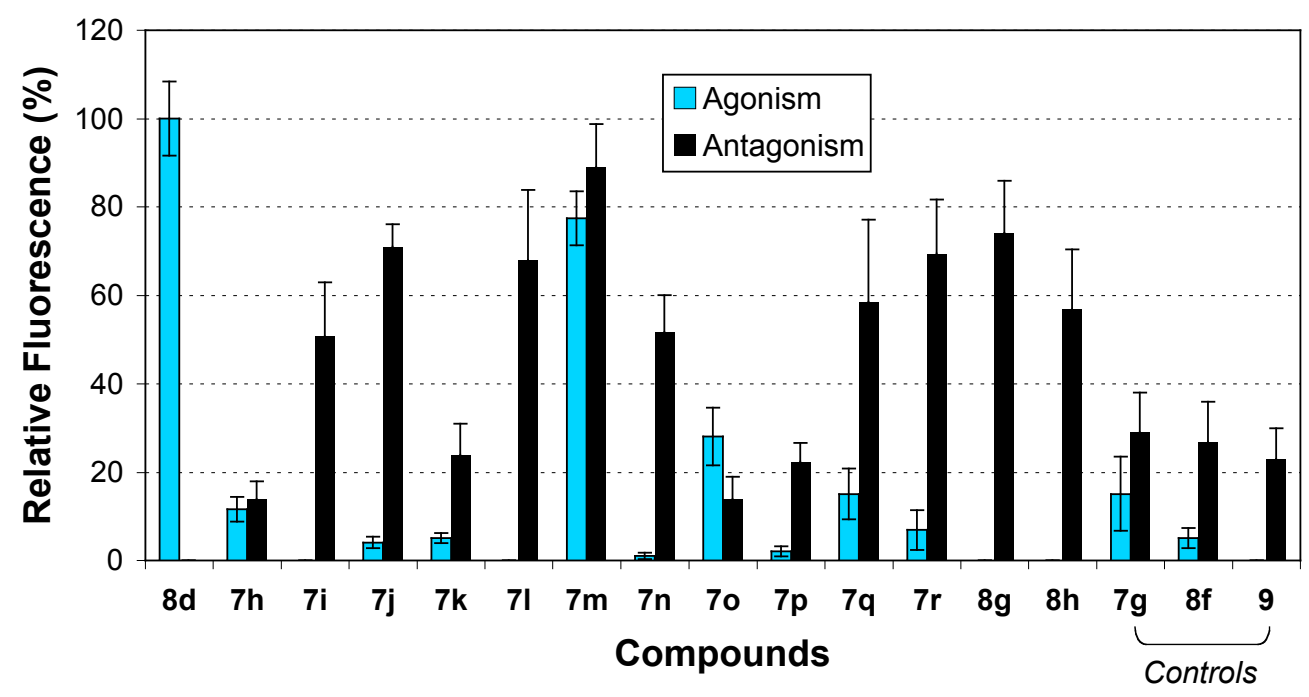

Figure S-4. P. aeruginosa reporter gene screening data for AHL derivatives AHL derivatives 7h-7r and 8f-8h. Data for control compounds $\mathbf{7 g}, \mathbf{8 f}$, and 9 are shown. Reporter strain: PAO-JP2(plasI-LVAgfp). ${ }^{6}$ Fluorescence reported as percentage relative to native ligand 8d (ODHL). Compound concentration in agonism assays: $1 \mu \mathrm{M}$. Compound concentration in antagonism assays: $400 \mu \mathrm{M}$ against $1 \mu \mathrm{M}$ native ligand $\mathbf{8 d}(\mathrm{ODHL})$. Error bars calculated from at least three replicate screens. ${ }^{13}$ 

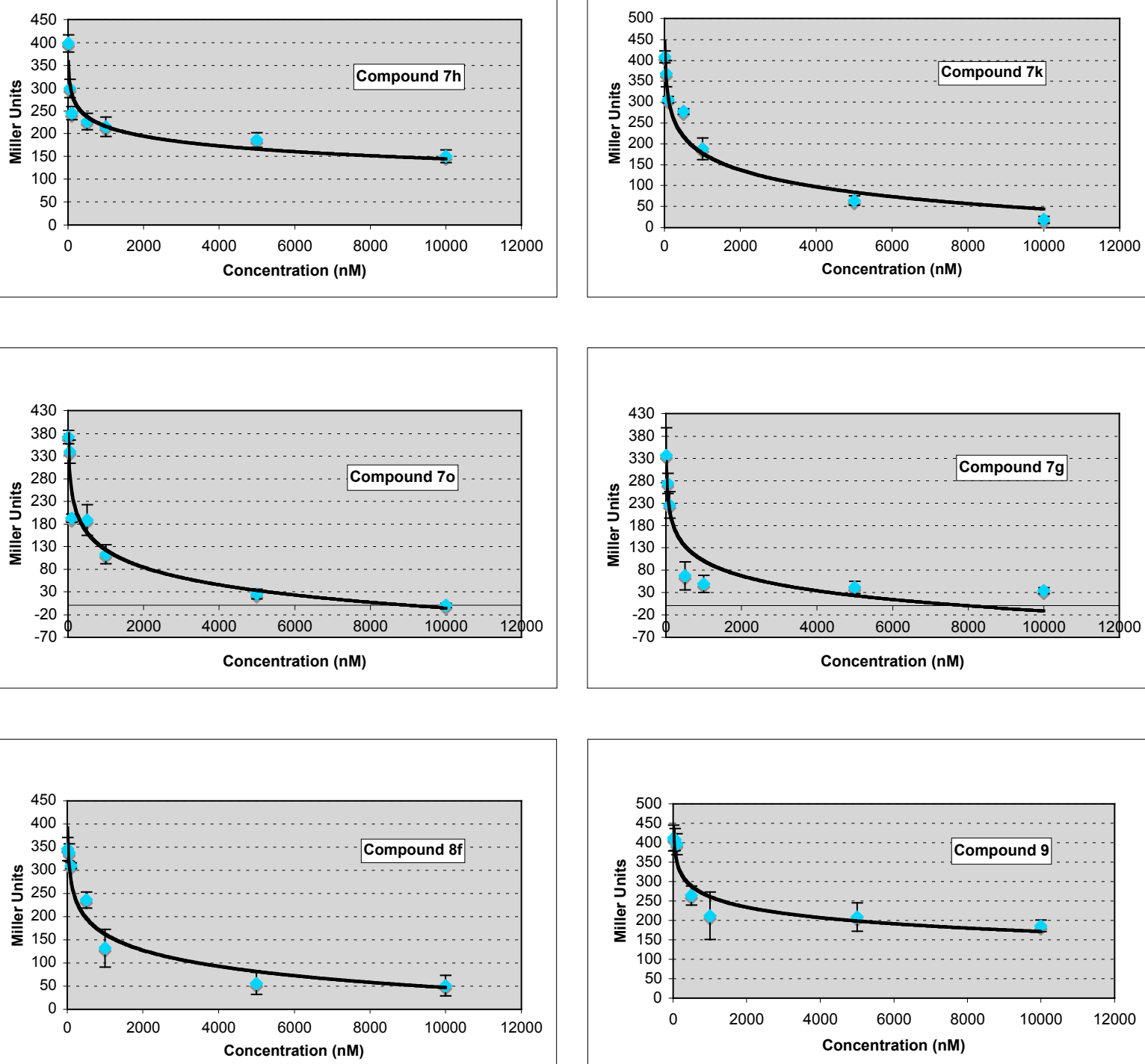

Figure S-5. Dose response antagonism screening data for AHL derivatives $\mathbf{7 h}, \mathbf{7 k}$ and $\mathbf{7 o}$ (top left) and control compounds $\mathbf{7 g}, \mathbf{8 f}$, and 9 (bottom right) in an A. tumefaciens reporter strain. Reporter strain: WCF47(pCF372). ${ }^{8}$ Miller units report relative $\beta$-galactosidase activity with ONPG as colometric substrate. Compounds screened at various concentrations against $100 \mathrm{nM}$ native ligand $\mathbf{8 b}$ (OOHL). Error bars calculated from at least three replicate screens. 

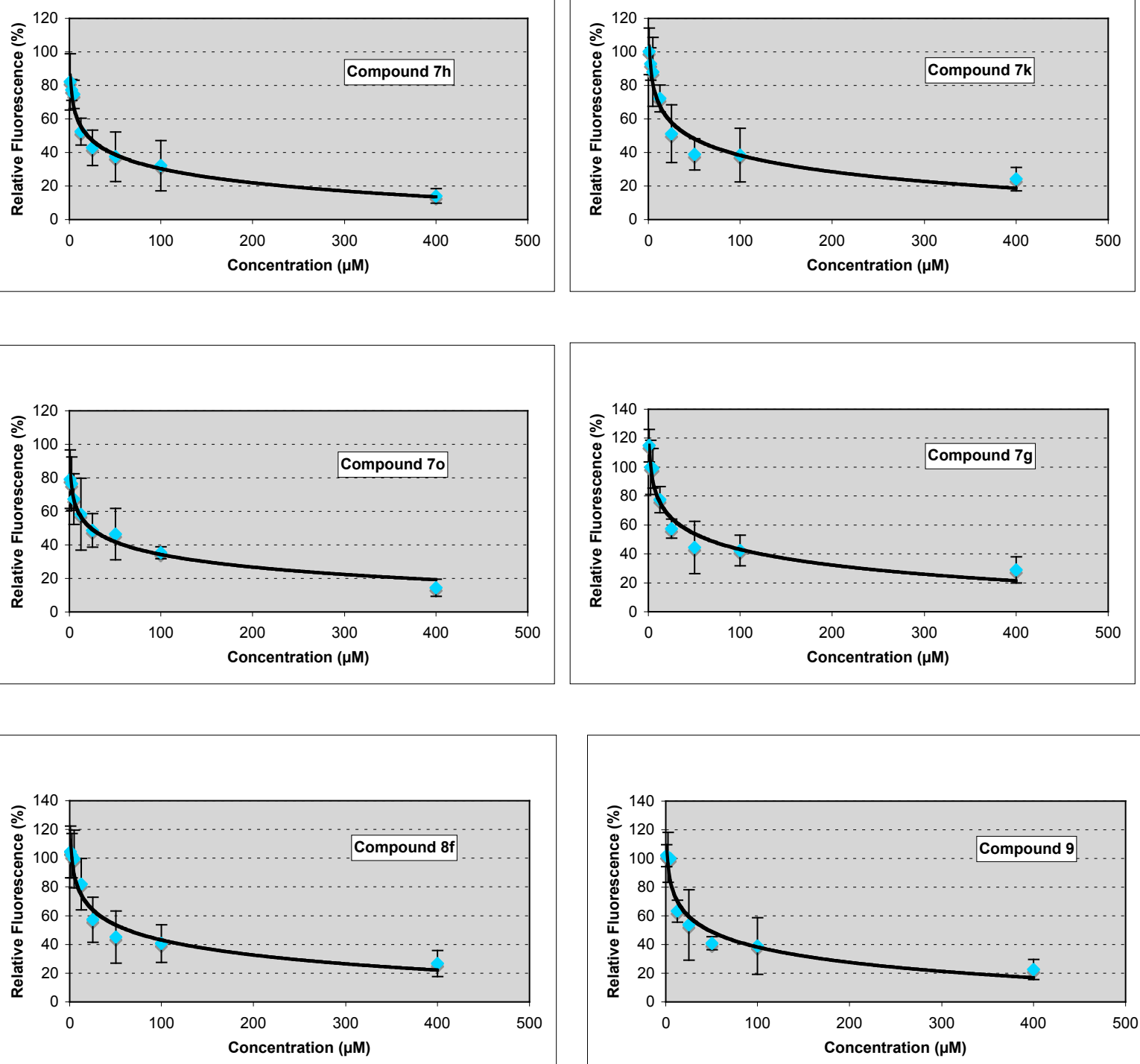

Figure S-6. Dose response antagonism screening data for AHL derivatives $\mathbf{7 h}, \mathbf{7 k}$ and $\mathbf{7 0}$ (top left) and control compounds $\mathbf{7 g}, \mathbf{8 f}$, and 9 (bottom right) in a $P$. aeruginosa reporter strain. Reporter strain: PAOJP2(plasI-LVAgfp). ${ }^{6}$ Fluorescence reported as percentage relative to native ligand $8 \mathbf{d}$ (ODHL). Compounds screened at various concentrations against $1 \mu \mathrm{M}$ native ligand 8d (ODHL). Error bars calculated from at least three replicate screens. 
Table S-2. Selected antagonism screening data and IC50 inhibition values for AHL derivatives 7h, 7k and $7 \mathbf{o}$ and control compounds $\mathbf{7 g}, \mathbf{8 f}$, and $\mathbf{9}$ in A. tumefaciens and $P$. aeruginosa reporter strains. ${ }^{a}$

\begin{tabular}{|c|c|c|c|c|c|c|}
\hline \multirow[t]{2}{*}{ compound } & \multicolumn{3}{|c|}{$\begin{array}{c}\text { A. tumefaciens } \\
\beta \text {-galactosidase activity } \\
\text { [Miller units] }\end{array}$} & \multicolumn{3}{|c|}{$\begin{array}{c}P . \text { aeruginosa } \\
\text { Relative fluorescence } \\
{[\%]^{b}}\end{array}$} \\
\hline & $10^{4} \mathrm{nM}^{c}$ & $100 \mathrm{nM}^{c}$ & IC50 $(\mu \mathrm{M})^{c, d}$ & $400 \mu \mathrm{M}^{e}$ & $12.5 \mu \mathrm{M}^{e}$ & $\mathrm{IC50}(\mu \mathrm{M})^{d, e}$ \\
\hline 8b: OOHL & $-{ }^{f}$ & $385 \pm 35^{g}$ & -- & - & -- & - \\
\hline 8d: ODHL & -- & -- & -- & -- & $100 \pm 8^{h}$ & -- \\
\hline $7 \mathrm{~h}$ & $150 \pm 14$ & $245 \pm 14$ & 1.1 & $14 \pm 4$ & $52 \pm 8$ & 14.8 \\
\hline $7 k$ & $19 \pm 8$ & $306 \pm 8$ & 1.0 & $24 \pm 7$ & $72 \pm 8$ & 33.1 \\
\hline 70 & $0 \pm 4$ & $193 \pm 9$ & 0.25 & $14 \pm 5$ & $58 \pm 21$ & 16.1 \\
\hline $7 g$ & $34 \pm 6$ & $226 \pm 30$ & 0.13 & $29 \pm 9$ & $78 \pm 9$ & 51.5 \\
\hline $8 f$ & $51 \pm 22$ & $310 \pm 6$ & 0.59 & $27 \pm 9$ & $82 \pm 18$ & 53.6 \\
\hline 9 & $186 \pm 15$ & $396 \pm 27$ & 4.7 & $23 \pm 7$ & $63 \pm 8$ & 37.3 \\
\hline
\end{tabular}

${ }^{a}$ A. tumefaciens strain: WCF47(pCF372); ${ }^{8}$ P. aeruginosa strain: PAO-JP2(plas/-LVAgfp). ${ }^{6}$ Relative to agonism by $8 \mathbf{d}$ at $1 \mu \mathrm{M}$; Set to $100 \%$. ' Screened against $100 \mathrm{nM} \mathbf{8 b}$. ${ }^{d}$ IC50 calculated from dose response data shown in Figures S-5 and S-6 using nonlinear regression sigmoidal dose-response curve fit at $95 \%$ confidence with GraphPad Prism software (v. 4.00). ${ }^{14}{ }^{e}$ Screened against $1 \mu \mathrm{M} \mathbf{8} \mathbf{d} .{ }^{f}$ Not applicable. ${ }^{g}$ Control: Agonism activity at $100 \mathrm{nM} \mathbf{8 b}$. ${ }^{h}$ Control: Relative agonism activity at $1 \mu \mathrm{M} \mathbf{8 d}$ (note: not at $12.5 \mu \mathrm{M}$ ). 
Static $\boldsymbol{P}$. aeruginosa biofilm assays. Assays were performed according to standard procedures reported by Iglewski and co-workers. ${ }^{6,10}$ In brief, an overnight culture of $P$. aeruginosa PAO1(pTdK-GFP) ${ }^{6}$ was diluted to an $\mathrm{OD}_{600}$ of 0.1 in fresh M9 medium containing $200 \mu \mathrm{g} / \mathrm{mL}$ carbenicillin. This diluted culture was added to a tube containing $50-\mu \mathrm{M}$ antagonist. Control biofilms were grown in which no antagonist was added. A sterilized glass coverslip was added to each tube, and the culture was incubated at $37{ }^{\circ} \mathrm{C}$ for $48 \mathrm{~h}$ without shaking. Coverslips were removed, washed with phosphate buffered saline, and examined using scanning laser confocal microscopy methods. Top-down $\mathrm{Z}$ series were collected over a distance of $\mathrm{ca} .100 \mu \mathrm{m}$. Images in Figure 2 in the text and Figures S-7-S-9 are representative of several experiments performed on separate days. Figures S-8 and S-9 show dose response biofilm inhibition data.
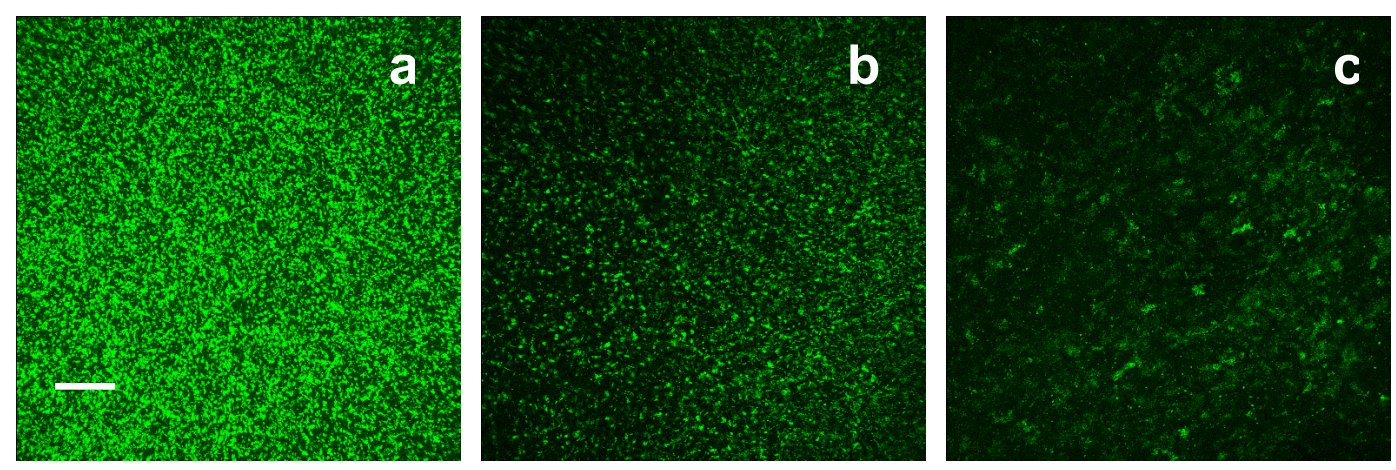

Figure S-7. Composite stacked scanning confocal laser micrographs of $P$. aeruginosa (PAO1(pLVAgfp) $)^{6}$ biofilms grown on glass slides for $48 \mathrm{~h}$ in the presence of synthetic ligands (at 50 $\mu \mathrm{M})$. Scale bar $=50 \mu \mathrm{m}$. a. untreated. b. Compound 7h. c. Compound 7o. 

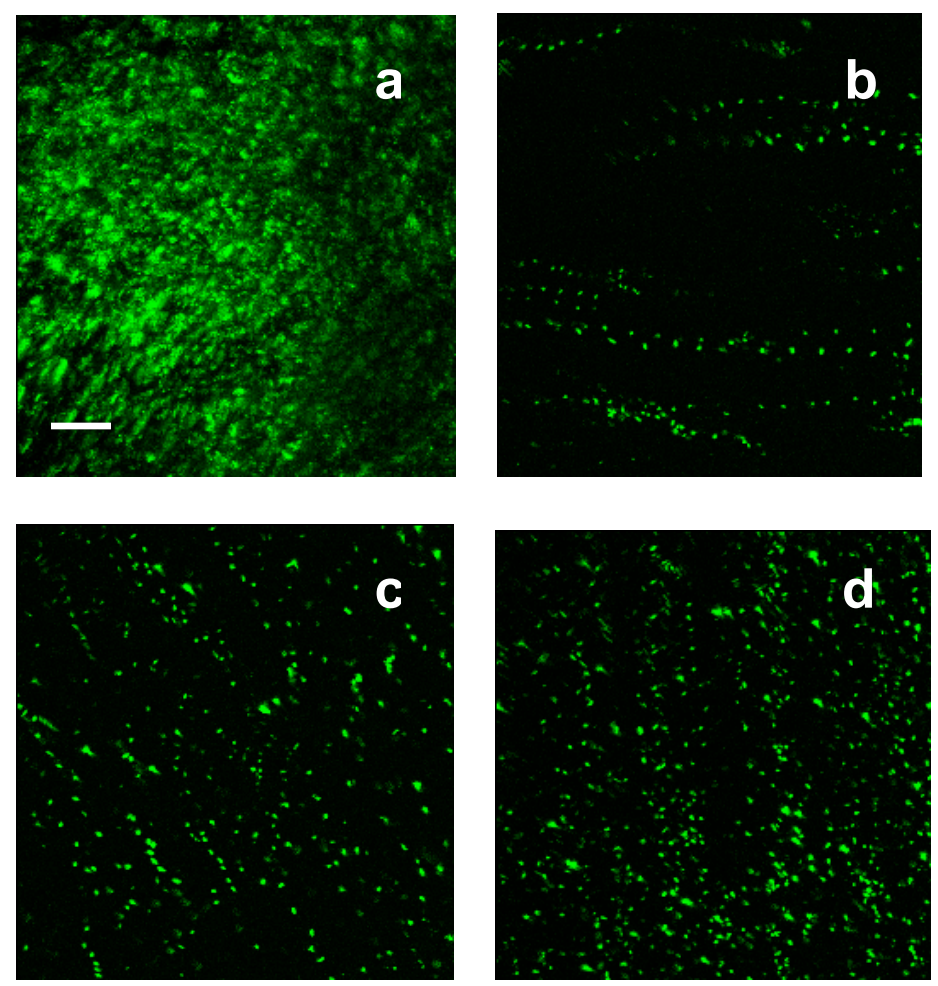

Figure S-8. Composite stacked scanning confocal laser micrographs of $P$. aeruginosa (PAO1(pLVAgfp) $)^{6}$ biofilms grown in the presence of AHL ligand 7o at various concentrations. Biofilms grown on glass slides for $48 \mathrm{~h}$. Scale bar $=10 \mu \mathrm{m}$. a. untreated. b. $50 \mu \mathrm{M}$ 7o. c. $25 \mu \mathrm{M}$ 7o. d. $12.5 \mu \mathrm{M} 7 \mathbf{0}$. 

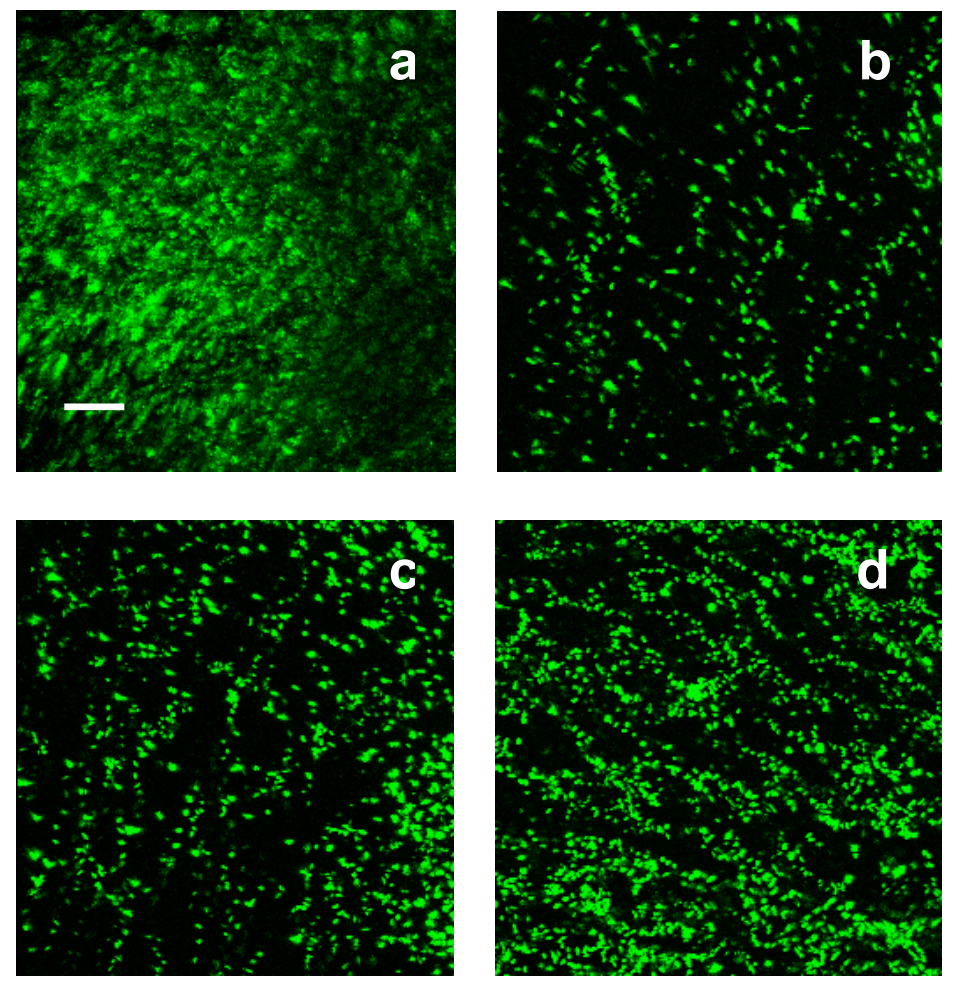

Figure S-9. Composite stacked scanning confocal laser micrographs of $P$. aeruginosa (PAO1(pLVAgfp) $)^{6}$ biofilms grown in the presence of AHL ligand $\mathbf{7 h}$ at various concentrations. Biofilms grown on glass slides for 48 h. Scale bar $=10 \mu \mathrm{m}$. a. untreated. b. $50 \mu \mathrm{M}$ 7h. c. $25 \mu \mathrm{M}$ 7h. d. $12.5 \mu \mathrm{M} 7 \mathbf{h}$.

\section{$\underline{\text { References and notes }}$}

(1) For further information about this MW system, see www.milestonesci.com/synthmicro.php

(2) For further information about this MW system, see http://www.cemsynthesis.com/

(3) (a) Barnick, J. W. F. K.; van der Baan, J. L.; Bickelhaupt, F. Synthesis 1979, 79, 787-788.

(b) Rathke, M. W.; Nowak, M. A. Synth. Commun. 1985, 15, 1039-1049.

(4) Carpino, L. A.; Han, G. Y. J. Org. Chem. 1972, 37, 3404-3409.

(5) For a description of this de analysis, see: www.chem.qmul.ac.uk/iupac/stereo/DE.html

(6) De Kievit, T. R.; Gillis, R.; Marx, S.; Brown, C.; Iglewski, B. H. Appl. Environ. Microbiol. 2001, 67, 1865-1873. 
(7) Miller, J. H. Experiments in Molecular Genetics; Cold Spring, 1972.

(8) Zhu, J.; Beaber, J. W.; More, M. I.; Fuqua, C.; Eberhard, A.; Winans, S. C. J. Bacteriol. 1998, 180, 5398-5405.

(9) (a) Reverchon, S.; Chantegrel, B.; Deshayes, C.; Doutheau, A.; Cotte-Pattat, N. Bioorg. Med. Chem. Lett. 2002, 12, 1153-1157. (b) Castang, S.; Chantegrel, B.; Deshayes, C.; Dolmazon, R.; Gouet, P.; Haser, R.; Reverchon, S.; Nasser, W.; Hugouvieux-CottePattat, N.; Doutheau, A. Bioorg. Med. Chem. Lett. 2004, 14, 5145-5149.

(10) Smith, K. M.; Bu, Y.; Suga, H. Chem. Biol. 2003, 10, 563-571.

(11) Griffith, K. L.; Wolf, R. E., Jr. Biochem. Biophys. Res. Commun. 2002, 290, 397-402.

(12) This software is available at no cost from: http://www.nephrology.iupui.edu/imaging/software.htm

(13) The antagonism activity of compound $\mathbf{7 p}$ in $P$. aeruginosa is the subject of an on-going study.

(14) This software is available at no cost from GraphPad Software, San Diego, CA USA: http://www.graphpad.com 